\title{
Impact of the Nanopore Size on Estimation of Gas-in-Place for Marcellus Shale Gas Reservoirs
}

\author{
Alexandra Power Stockdale
}

Follow this and additional works at: https://researchrepository.wvu.edu/etd

\section{Recommended Citation}

Stockdale, Alexandra Power, "Impact of the Nanopore Size on Estimation of Gas-in-Place for Marcellus Shale Gas Reservoirs" (2015). Graduate Theses, Dissertations, and Problem Reports. 6730.

https://researchrepository.wvu.edu/etd/6730

This Thesis is protected by copyright and/or related rights. It has been brought to you by the The Research Repository @ WVU with permission from the rights-holder(s). You are free to use this Thesis in any way that is permitted by the copyright and related rights legislation that applies to your use. For other uses you must obtain permission from the rights-holder(s) directly, unless additional rights are indicated by a Creative Commons license in the record and/ or on the work itself. This Thesis has been accepted for inclusion in WVU Graduate Theses, Dissertations, and Problem Reports collection by an authorized administrator of The Research Repository @ WVU. For more information, please contact researchrepository@mail.wvu.edu. 


\title{
Impact of the Nanopore Size on Estimation of Gas-in-Place for Marcellus Shale Gas Reservoirs
}

\author{
Alexandra Power Stockdale \\ Thesis submitted \\ to the Statler College of Engineering and Mineral Resources \\ at West Virginia University
}

in partial fulfillment of the requirements for the degree of

Master of Science in

Petroleum and Natural Gas Engineering

Kashy Aminian, PhD, Chair

Samuel Ameri, Prof

Keith Heasley, PhD

Department of Petroleum and Natural Gas Engineering

Morgantown, West Virginia

2015

Keywords: Gas-In-Place, Nanopores, Dry-Gas Reservoir, Marcellus Shale, Size of Pores, Pore Proximity, Critical Temperature, Critical Pressure, Correlations Copyright 2015 Alexandra Power Stockdale 


\title{
ABSTRACT \\ SIZE EFFECTS OF NANOPORES IN DRY-NATURAL GAS RESERVOIRS OF THE MARCELLUS SHALE ON GAS-IN-PLACE CALULATIONS
}

\author{
Alexandra Power Stockdale
}

Nanopores, pores less than 10 nanometers as defined for this study, have significant impact on the flow, production, and storage potential. These impacts, in turn, effect gas-in-place calculations and overall reservoir estimations.

This research studies a dry-gas reservoir in the Marcellus Shale. A dry-gas reservoir exhibits the same behavior as a wet gas reservoir under confinement effects of nanopores. Therefore, the published correlation for estimating the impact of nanopore size on the critical hydrocarbon properties are utilized in this study.

By use of the gas compositional analysis, the effects on the gas-in-place calculations of the confined pores were compared to the traditional reservoir calculations for unconfined pores. After applying the corrections to the critical temperature and pressure, the z-factor was found by the use of a z-factor chart. This z-factor was incorporated into the gas-in-place calculations and created an easily interpreted reservoir result in millions of cubic feet of gas.

Concluding the study, it was found that the gas-in-place calculations deviate by up to $8 \%$ when using confined pores versus unconfined pores. The pore sizes of $2 \mathrm{~nm}, 4 \mathrm{~nm}$, and $5 \mathrm{~nm}$ changed the gas-in-place calculation by $-8 \%, 2 \%$ and $6 \%$ respectively when compared to the unconfined pore size range of $10 \mathrm{~nm}-100 \mathrm{~nm}$. The actual field data for the calculations created a simple comparison of gas-in-place calculations of $2 \mathrm{~nm}, 4 \mathrm{~nm}, 5 \mathrm{~nm}$, and >10nm pore sizes, yielding 2 MMCF, 2.2 MMCF, 2.3 MMCF and 2.16 MMCF of gasin-place per acre foot. 


\section{Table of Contents}

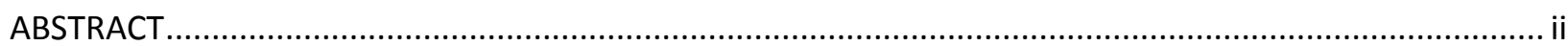

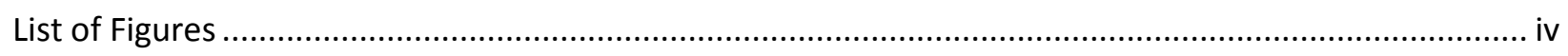

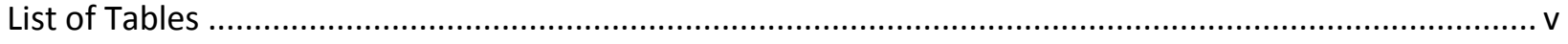

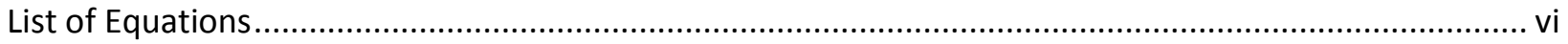

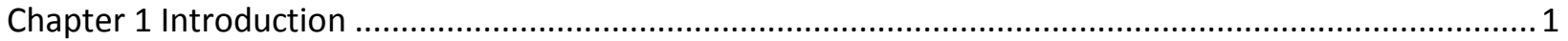

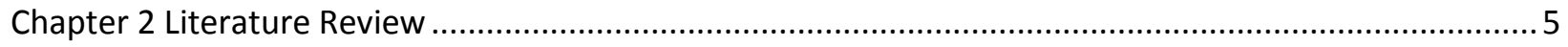

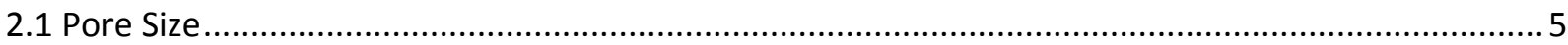

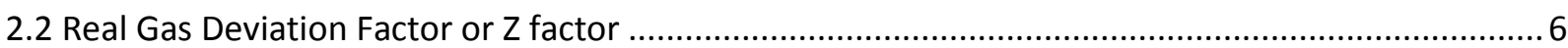

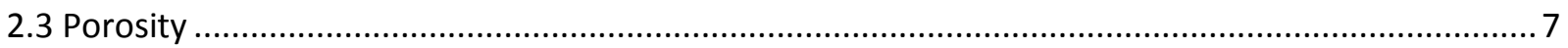

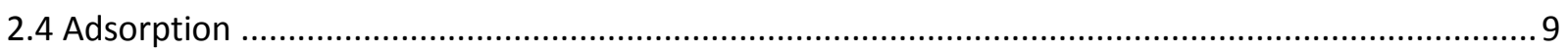

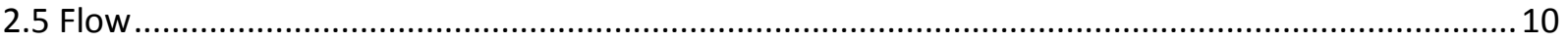

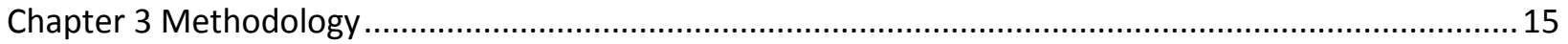

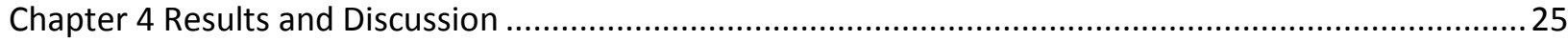

4.1 Nanopore Size Effects on the Pseudo Reduced Temperatures and Pressures................................25

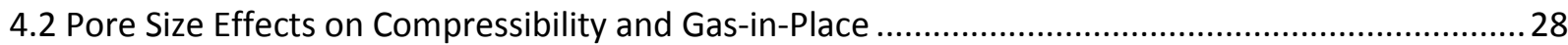

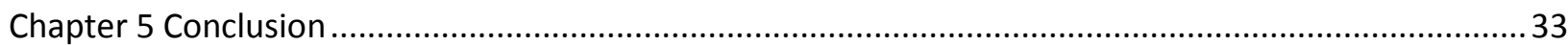

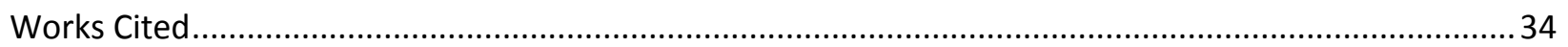

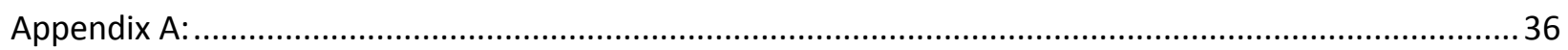




\section{List of Figures}

Figure 3-1: Critical Pressure Correlation for Molecular Weight (Devegowda, 2012) ..............................22

Figure 3-2: Critical Temperature Correlation for Molecular Weight (Devegowda, 2012)....................... 23

Figure 4-1 Flow chart and organization for the study of nanopore effects on gas-in-place. ...................25

Figure 4-2 Study \#1 Pseudo reduced temperature results for the changing reservoir pressures..............26

Figure 4-3 Study \#2 Pseudo reduced temperature results for the changing reservoir pressures..............26

Figure 4-4 Study \#1 Pseudo reduced pressure results for the changing reservoir pressures and pore sizes.

Figure 4-5 Study \#2 Pseudo reduced pressure results for the changing reservoir pressures and pore sizes.

Figure 4-6 Study \#1 Compressibility results for the changing reservoir pressures and pore sizes. ...........29

Figure 4-7 Study \#2 Compressibility results for the changing reservoir pressures and pore sizes. ...........29

Figure 4-8 Study \#1 Gas-in-place results for the changing reservoir pressures and pore sizes. ................30

Figure 4-9 Study \#2 Gas-in-place results for the changing reservoir pressures and pore sizes. ................ 30 


\section{List of Tables}

Table 2-1 General Marcellus Shale Porosity (Chesapeake, 2008). ...................................................... 7

Table 3-1 Parameters used in the Gas-in-Place Calculations.............................................................. 17

Table 3-2 Study \#1 included separator gas compositional analysis from gas produced in the Marcellus

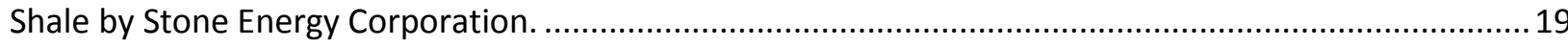

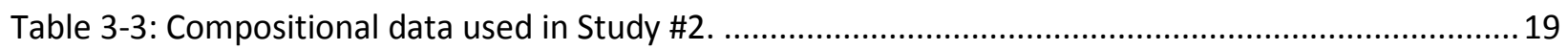

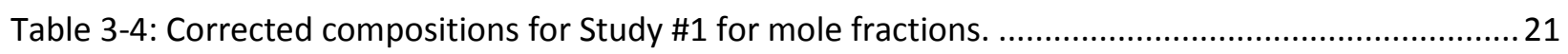

Table 3-5: Corrected compositions for Study \#2 for mole fractions. .....................................................21

Table 3-6 Formation pressures and temperatures used for both of the compositions...........................24

Table 4-1 Percent change of the gas-in-place comparing the composition \#1 and \#2 when increasing the

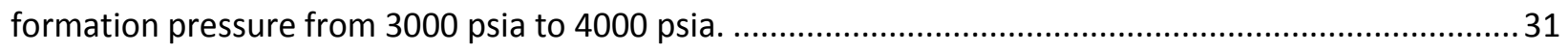

Table 4-2 Percent change of gas-in-place between composition \#1 and \#2 .......................................... 31

Table 4-3 Comparison of the changes to the gas-in-place for the changing composition and pore size... 32

Table 5-1 Percent change of the gas-in-place found in the Marcellus Shale from the unconfined pore size

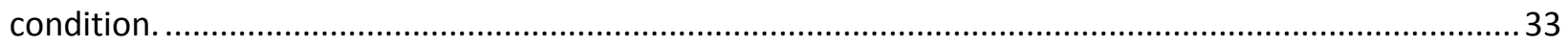




\section{List of Equations}

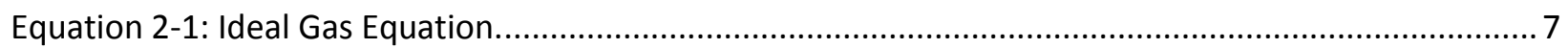

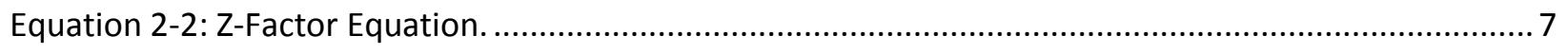

Equation 2-3: Reduced Temperature Equation. ........................................................................... 13

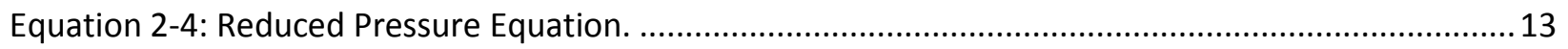

Equation 2-5: Pseudocritical Temperature Equation.................................................................... 13

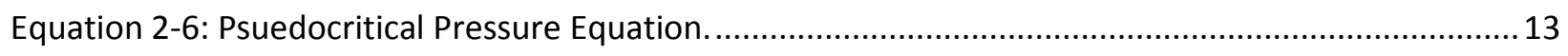

Equation 2-7: Shift of Critical Temperature Equation................................................................... 14

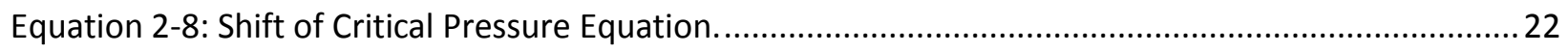

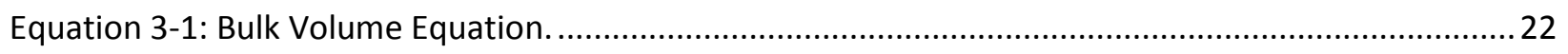

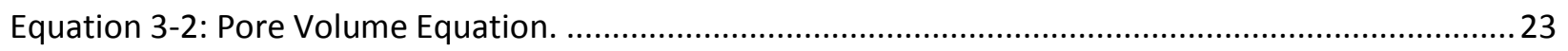

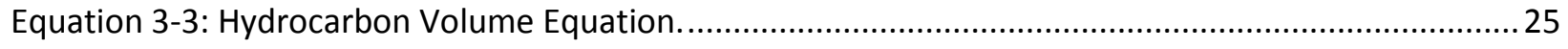

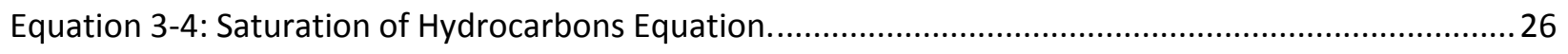

Equation 3-5: Saturation of Hydrocarbons Equation Using Irreducible Water Saturation. ...................... 26

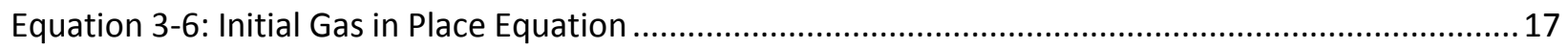

Equation 3.7: Initial Gas in Place Equation Using Irreducible Water Saturation ..................................... 17 


\section{Chapter 1 Introduction}

Nanopores have effects on the gas storage and well-life in shale reservoirs that unconfined pores do not. The nanopores may increase or decrease the gas-in-place estimation. There are approximately 354 trillion cubic feet of gas reserves within the Marcellus Shale so it is integral that the United States can have a good estimate of the gas-in-place in each reservoir.

Although there are vast amounts of natural gas in the Marcellus Shale, the changing economic market for the gas in the United States places an importance on knowing the gas-in-place in an area prior to drilling. Previously, when the natural gas prices were high, the production of natural gas was so lucrative that a $10-12 \%$ difference in the estimates of natural gas-in-place would not hurt a company economically. With the lower prices in natural gas, the margins to make money become slimmer and it becomes more important to have an accurate estimate of how much gas a reservoir contains.

The properties of the gas like compressibility factor, adsorption, and viscosity will be studied for different size pores. The pore size effects all of these properties and these properties have an impact on gas-in-place estimation. Based on the resultant properties, the gas-in-place will be calculated by applying the volumetric method. Although, this topic has been the focus of previous papers, these papers were looking into gas condensate and oil reservoirs. In the aforementioned gas condensate papers the results revealed that storage potential and well-life were significantly underestimated (Reed \& Wang, 2009). Pore structure determines storage capacities and the flow of gas from the matrix (Curtis, Ambrose, \& Sondergeld, 2010). Most of the gas storage occurs in the matrix in finegrained hydrocarbon reservoirs (Curtis et al., 2010). Pore location, whether the pore is in 
the organic or inorganic material, determines the wettability of the shale (Curtis et al., 2010). Along with the pore location, the increase and decrease in pore sizes changes the physics of the fluid flow. Changing the physics of the fluid flow terminates the ability of Darcy's Law to describe fluid flow (Curtis et al., 2010). Small pores, pores a few nanometers in diameter, may have large amounts of adsorbed gas content compared with the free gas content (Ambrose, Hartman, \& Akkutlu, 2011). The pores play such a significant role that even the shape of pores can affect the storage. Round pores would be much less prone to collapse from an external pressure than linear or crack-like pores (Curtis et al., 2010).

Deliverability is the tested and proved ability of a well to produce. A realistic expectation of deliverability is hard to conject when the reservoir is 8,000 feet below surface elevation. Deliverability increases with maturity in the reservoir but there is a gas-generation window of thermal maturity. Gas shales contain amounts of organic matter in disparate grades of maturation. The window is different for different shales, but deliverability of shales depends on the composition, porosity and permeability.

Grain size less than 5 micrometers is usually the cut-off to define microstructure in shale. There are many problems with defining shales and their typical or "standard" parameters because the components cannot be identified by simply looking at them. Shale microstructure is mainly explored by use of Scanning Electron Microscopy (SEM), X-ray imaging, Transmission Electron Microscopy (TEM) or Scanning Acoustic Microscopy (SAM). Most recently three dimensional images have been developed with a resolution of 4-5 $\mathrm{nm}$ pores (Sondergeld, Ambrose, \& Rai, 2010). 
Anisotropy, is one thing property inherent to. It causes seismic imaging problems and directly affects AVO (Amplitude Variation with Offset), which tries to identify pore fluid and hydrocarbon interpretations. Estimating gas-in-place and deliverability can prove troublesome owing to pore volume inaccuracies. The pore volumes are usually measured with direct and indirect methods. The direct methods involve visual assessments and can be bounded by two dimensions. Using only two dimensions is a large issue because of the complex nature of the pore structure (Sondergeld et al., 2010). The indirect methods use gas or fluids to flow through the pore space and interpret porosity. Grain size in shales are $<1 / 256$ millimeters or $<39$ micrometer and can create challenges in measurement and description (Sondergeld et al., 2010). The NETL (National Energy Technology Laboratory), like many laboratories that specialize in shale gas research, in Morgantown West Virginia has capabilities to go to micrometers but they do not have the ability to see nanometers. Shale has such small grain sizes caused by compaction when it was being formed. This compaction creates lots of anisotropic mechanical, elastic, and transport properties (Sondergeld et al., 2010).

The Marcellus Shale was formed by large amounts of Plankton accumulating on the sea floor and being compacted over approximately 400 million years. This plankton was broken down and decomposed and along with other organic material, like sea plants, it formed kerogen. Kerogen is a mixture of organic materials and the higher the kerogen content the higher the BTU value of the shale. The kerogen content is often reported as Total Organic Content (TOC) as a weight percentage. Organics are important to any economic assessment because they lower density, increase porosity, provide the source 
of the gas, impart anisotropy, change wettability and enable adsorption (Sondergeld et al., 2010). 


\section{Chapter 2 Literature Review}

\subsection{Pore Size}

Methane gas shows the effects of confinement on the critical properties when pore diameters are under 10nm (Rezaveisi, Javadpour, \& Sepehrnoori, 2013). Shale gas can be found in pore sizes from 0.5 to $100 \mathrm{~nm}$ so the pore proximity must be considered (Devegowda, 2012). Pore proximity is the proximity of a molecule to a molecule or a molecule to a pore wall within the pore. Conventional reservoirs have much larger pore sizes so the interaction between the hydrocarbon molecules and pore walls is insignificant because the pore sizes are larger than molecular mean free paths (Jin, Ma, \& Jamili, 2013).

Pore sizes in shales are not homogeneous. This homogeneity is significant because when the sizes of the pores change, the flow within the pores change so using an average pore size when calculating gas-in-place will not be accurate. Beskok and Karniadakis (1999) have attempted to correct this problem by looking at the pores like a bundle of tubes with different diameters (Michel, 2011) (Beskok \& Karniadakis, 1999).

Scanning-electron-microscopy was used to confirm pore radii ranging from a few nanometers to tens of nanometers in shales (Curtis et al., 2010). Because Reynolds number is a function of grain diameter and Darcy's Law depends on the Reynolds number, when the grain size gets to a few nanometers the gas flow through porous media can no longer be described under the assumption of no-slip (Darcy's Law). The simplified models with Darcy's Law can underestimate productive well life for infinite acting flow so they must be modified to account for the flow regimes in nanopores. Nanopores have different flows caused by the interaction of the molecules with the pore walls and 
transitions from the no-slip to slip regimes (Michel, 2011). The Beskok-Karniadakis Model (1999) is usually selected for describing the transport during production from shale gas formations because it describes all four expected regimes in capillary flow (Michel, 2011).

The permeability of the Marcellus Shale is also affected by pore size. Permeability in the Marcellus Shale decreases with an increase in confining pore pressure (Reed \& Wang, 2009). Reduction in porosity creates confining pore pressure and the effect of the confining pore pressure is create by the Klinkenberg (1941) slippage effect (Reed \& Wang, 2009). The Klinkenberg (1941) slippage effect says that, "gas flow becomes nonviscous when pore sizes are 1 to 1,000 times larger than the mean free path of gas molecules (Javadpour, Fisher, \& Unsworth, 2007)."

\subsection{Real Gas Deviation Factor or Z factor}

The ideal gas equation, equation 2.1, can also be used to describe natural gas. The natural gas behavior is not drastically different from an ideal gas so a correction factor can be used to adjust the ideal gas equation to suite a real gas. The correction factor that is used is called the $z$ factor or compressibility factor. This factor is also sometimes called the gas deviation factor because it describes the deviation of a real gas from an ideal gas. The $z$ factor can also be expressed as shown in equation 2.2. Equation 2.2 shows that the $z$-factor is simply the volume actually occupied by a real gas over the volume occupied by an ideal gas at the same pressure and temperature (McCain, 1990).

$p V=z n R T$ 
$Z=\frac{V_{\text {real gas }}}{V_{\text {ideal gas }}}$

Where, $\mathrm{p}$ is pressure, $\mathrm{V}$ is volume, $\mathrm{z}$ is compressibility, $\mathrm{n}$ is the molar mass or number of moles, $\mathrm{R}$ is universal gas constant, and T is temperature.

The $z$ factor or real gas deviation factor is calculated with pressure, temperature and the gas constant. Pressure and temperature both change under confined conditions. Therefore, calculations of transport, storage, and gas-in-place can be greatly affected by confinement because of the effects it has on the critical properties. The work of Devegowda (2012) shows the adjustment of critical values changes the real gas deviation factor significantly. Furthermore, a nanoporous reservoir many have enhanced gas transport resulting from the lower viscosity because of confinement effect (Devegowda, 2012).

\subsection{Porosity}

$\mathrm{Hg}$ porosimetry has shown that the porosity of the shales is largely determined in the pore volume development in pores less than 10um (Bustin et al., 2008). Porosity values of gasshale systems range from 2 to 15\% (Curtis J., 2002). Chesapeake (2008) conducted a study using an assumed porosity of $10 \%$ in organic matter, and the total porosity and TOC values for Marcellus Shale in Appalachian Basin as shown in Table 2-1, estimated porosities in organic matter are $1.2 \%$ of the bulk volume. That is $18.5 \%$ of all pores in the Marcellus Shale are in organic matter. These values increase with the assumed porosity in organic matter.

Table 2-1 General Marcellus Shale Porosity (Chesapeake, 2008).
Item
Marcellus Shale 


\begin{tabular}{|c|c|}
\hline Total porosity of shale & $6.5 \%$ \\
Assumed Porosity in Natural & $<0.5 \%$ \\
Fractures & $<0.2 \%$ \\
\hline $\begin{array}{c}\text { Assumed Porosity in Hydraulic } \\
\text { Fractures }\end{array}$ & $\sim 12 \%(6 \mathrm{wt} \%)$ \\
\hline Total Organic Content (TOC) & $10 \%$ \\
\hline Assumed porosity in organic matter & $\sim 1.2 \%$ \\
\hline Porosity of organics in shale & $>4.6 \%$ \\
\hline Porosity in nonorganic rock matrix & \\
\hline
\end{tabular}

Shales are made up of the nonorganic matter and the organic matter, both forming complicated pore matrices. During stimulation or fracturing, these pore networks may be opened and connected to each other, but they also may not open making the porosity and pore-volume values in natural and hydraulic fractures difficult to measure or estimate. Organic matter pore volumes are usually estimated by assuming they are a function of TOC (total organic content) and the porosity in the organic matter. The porosity in the organic matter can play an important role in the higher-than-expected gas production from shales (Reed \& Wang, 2009).

The porosity of shales can be divided into two major groups. The shale with pore sizes from 10 to $1000 \mathrm{~nm}$ have little porosity while the pores with sizes less than $10 \mathrm{~nm}$ have high porosity (Bustin et al., 2008). 


\subsection{Adsorption}

Adsorption is the accumulation of gases or liquids on the surface of a solid. Shales are made up of four types of solid porous media: nonorganic matrix, organic matter, natural fractures, and hydraulic fractures. Adsorption is commonly noticed in organic matter with pores sizes ranging from $5-1,000 \mathrm{~nm}$. Organic matter also has 5 times higher porosity than nonorganic (Reed \& Wang, 2009). While adsorbed gas may increase the amount of hydrocarbons in the organic matter, it may actually hinder production because the layer of adsorbed gas increases drag on gas molecules which then decreases permeability (Reed \& Wang, 2009).

Although organic matter typically has higher porosity than other matter it sometimes has such small pores that only diffusion will enable flow (Reed and Wang, 2009). Diffusion is defined for this paper as hydrocarbons moving within the solid part of the rock, not as free gas, from high pressure to low pressure. Diffusion is the movement of the hydrocarbons from a high concentration area to a low concentration area.

When shale is undisturbed and under a constant pressure or at equilibrium, the hydrocarbon can be distributed throughout the rock as compressed gas, or it may lay on the surface of the kerogen materials as adsorbed gas and dispersed in the kerogen materials as dissolved gas (Bustin et al., 2008). When a reservoir is tapped by drilling a well or inducing a fracture, the equilibrium is disturbed, and molecules start flowing toward the low pressure zone. The molecules do not all flow at once though, first, the free gas or compressed gas is produced. Then, the adsorbed gas on the exterior of the kerogen walls desorb. The desorption allows the gas to expand and increases pore pressure. The gas will then flow from the increased pressure areas to the areas where the gas is being 
produced and the pressure is lower. This desorption of gas allows for even the tiniest of pores to produce some gas.

The volume of adsorbed gas in shales is reliant on surface area, pressure, temperature, and sorption affinity (Bustin et al., 2008). With pores in the nanometer size range, the surface area is greatly increased. The smaller pore sizes also mean that the amount of free gas decreases and the adsorbed gas storage capacity increases. Generally, for pores smaller than $0.01 \mathrm{um}$, the adsorbed gas storage surpasses the compressed gas storage (Beliveau, 1993). Nanopores with sizes in the 3-100 nm range have a portion of the total pore volume that is occupied by a finite-size adsorption layer and not available for the free gas molecules (Ambrose, Hartman, \& Akkutlu, 2011). Adsorption in gas shales

is dependent on reservoir temperature and pressure and the abundance, maturity, and type of kerogen (Bustin et al., 2008).

For reservoirs with a large amount of the gas in the form of adsorbed gas, the gas-inplace calculation is usually overestimated. The over-estimation can be as high as $40 \%$ (Ambrose et al., 2011).

\subsection{Flow}

There are four types of fluid flows in gas shales: (1) free gas flow, (2) desorption, (3) diffusion, and (4) imbibition suction. Free gas is the gas that is easily produced from the pores and exists in a gaseous phase and not as a solution or dissolved in reservoir fluids. Free gas flow can be Darcy or Non-Darcy type flow. The Darcy type flow is usually found in natural and hydraulic fractures while the non-Darcy type is found in the matrices as a result of the slippage effect (Reed \& Wang, 2009). The slippage effect is a theory to describe the interaction between the pore wall and hydrocarbons that are "slipping" by it. 
When the pore size is reduced to be almost the size of the mean free path of a hydrocarbon molecule, then the molecule will have more interaction with the pore wall and may "slip" when it touches the pore wall (Rushing, Newsham, \& Fraassen, 2003).

Adsorbed gas is attached to the surface of the pores. When the pressure is lowered in the reservoir, after the free gas is produced, the adsorbed gas is released and desorption occurs. Diffusion is similar to desorption in that when the molecules as free gas and adsorbed gas are produced there is less of a concentration of molecules. So the molecules that are trapped in the matrix, usually in the nanopores, travel from the high concentration areas to the low concentration areas. This occurs through low permeability zones.

Lastly, the imbibition suction occurs when the reservoir has low initial water saturation (subirreducible initial water saturation) (Bennion \& Thomas, 1996). This subirreducible initial water saturation can prevent water from being produced and create a suction of water. Although, oil and condensate reservoirs are also subject to imbibition suction, this will not be emphasized in this research because the focus is on dry-gas reservoirs.

\subsection{Critical Temperature and Critical Pressure}

Natural gas is essentially just an energy source and because temperature is a physical measure of kinetic energy of a material it makes sense to describe a gas reservoir with the temperature (McCain, 1990). Kinetic energy increases when temperature increases and heat is added to a material. Increasing kinetic energy also causes an increase in molecular motion, moving the molecules of gas further apart (McCain, 1990). 
Pressure is also used when explaining a reservoir. Pressure increases with confinement because pressure is a description of the number of times the particles of a gas hit the pore wall or wall of the container (McCain, 1990).

Critical temperature and critical pressure are words commonly used when describing gas inside a reservoir. The phases of the gas are defined by the temperature and pressure at which the phases change. The phase diagram in fig. 2-1 should help to clarify where the phases begin and end. The limit where the gas turns to liquid is called the critical point, point $C$ in fig. 2-1. The temperature and pressure at the critical point are called the critical temperature and critical pressure.

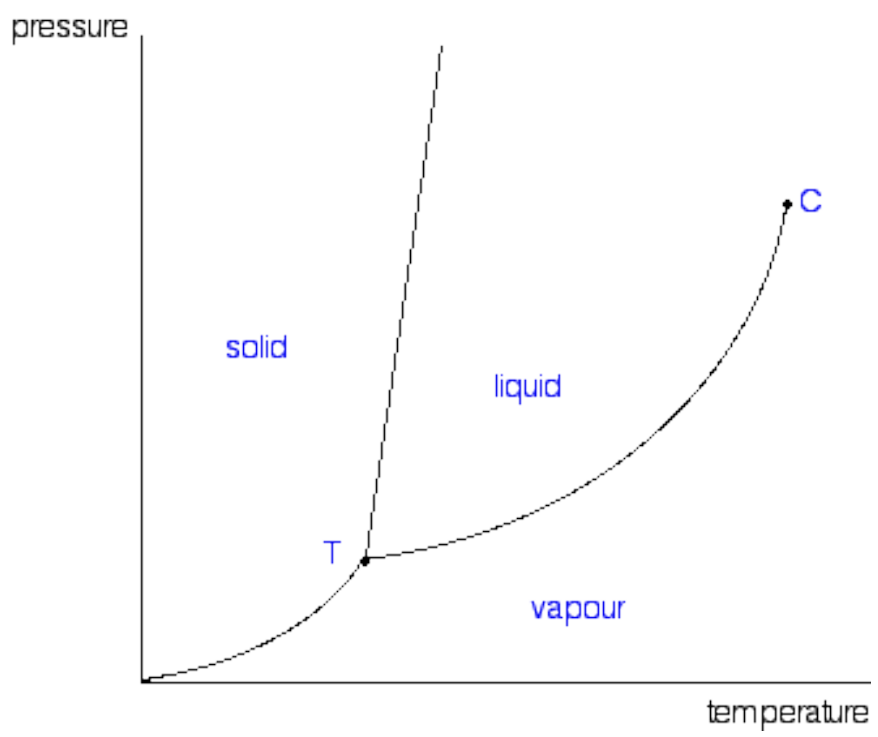

Figure 2-1 Typical phase diagram of a pure substance (McCain, 1990).

The reduced temperature and reduced pressure are the temperature and pressure normalized at the critical point. The equations for the critical temperature and critical pressure are shown in equation 2.3 and 2.4 respectively. 
$T_{r}=\frac{T}{T_{c}}$

$p_{r}=\frac{p}{p_{c}}$

Where $T_{r}$ and $p_{r}$ are reduced temperature and reduced pressure, $T$ is temperature, $p$ is pressure, $T_{c}$ is critical temperature, and $p_{\mathrm{c}}$ is critical pressure.

$T_{p c}=\frac{T}{T_{p c}}$

$p_{p r}=\frac{p}{p_{p c}}$

Equation 2.5 and 2.6 show the pseudocritical temperature and pseudocritical temperature formulas. The pseudocritical temperature and pressure are used to find the compressibility of a natural gas because a natural gas is a mixture of many components. The pseudocritical temperature and pressures are not the critical points for the mixture, but they are the values that are needed to compare the corresponding states of different gases on the z-factor chart (shown in Appendix A).

According to Ma (2013), the critical temperature and critical pressure under nanopore confinement are changed by the molecule-pore wall interactions. He also mentions that when studying pore sizes from 10 to $2 \mathrm{~nm}$ the two-phase region of a wet-gas shrinks and makes the wet-gas behave like a dry gas (Ma, Jin, \& Jamili, 2013).

Therefore, the work of Devegowda (2012) on the phase behavior and changes to critical properties of gas condensates in shales due to pore proximity effects. Devegowda showed that there are quantified changes in the critical properties from the changing pore sizes and he provided correlations to explain the changes. He used equations 2.7 and 2.8 from the work of Singh et al. (2009) to show the shift of critical temperature and pressure. 
$\Delta T_{c}=\frac{T_{c b}-T_{c p}}{T_{c b}}$

$\Delta P_{c}=\frac{P_{c b}-P_{c p}}{P_{c b}}$

Where $P_{c p}$ and $T_{c p}$ are the critical pressure and temperature in confined pores and $P_{c p}$ and $T_{c p}$ are the corresponding values in bulk.

Devegowda (2012) improves on the work of Singh et al. (2009) and uses the numerical experimental data from Singh et al. (2009) but Devegowda (2012) extrapolated the data to heavier compounds on the basis of their corresponding molecular weights. The figures 2.2 and 2.3 show the extrapolated deviations in critical temperature and pressure for hydrocarbon molecules from methane through n-decane (up to the molecular weight of 250) for pore diameters of $2 \mathrm{~nm}, 4 \mathrm{~nm}$, and 5nm (Devegowda, 2012).

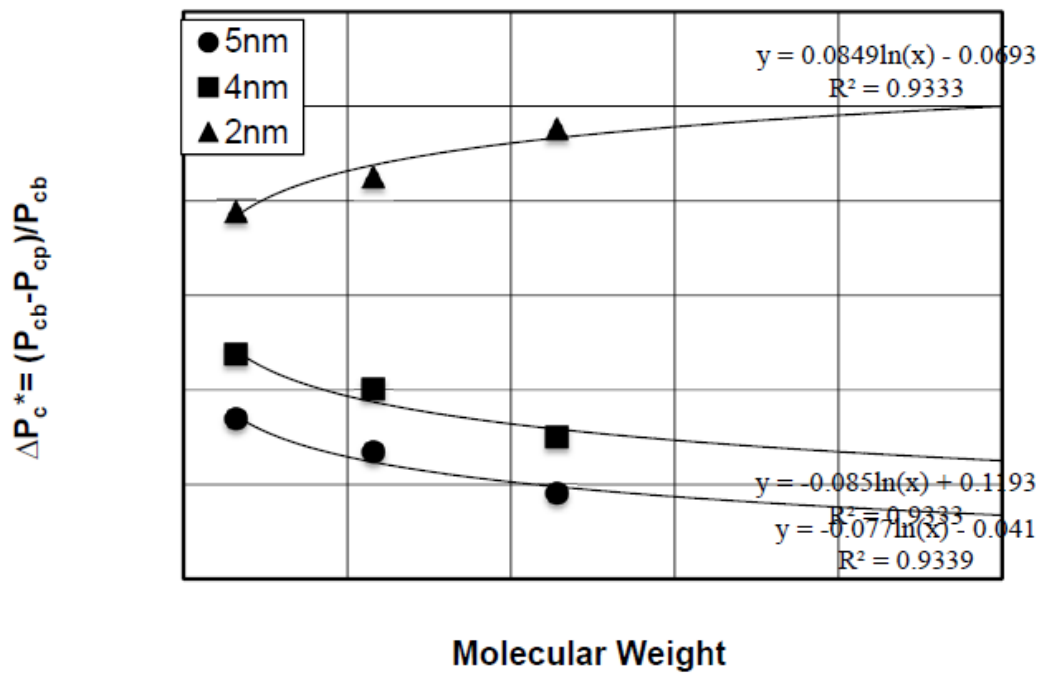

Figure 2-2 Relative deviation of critical pressure (Devegowda, 2012). 


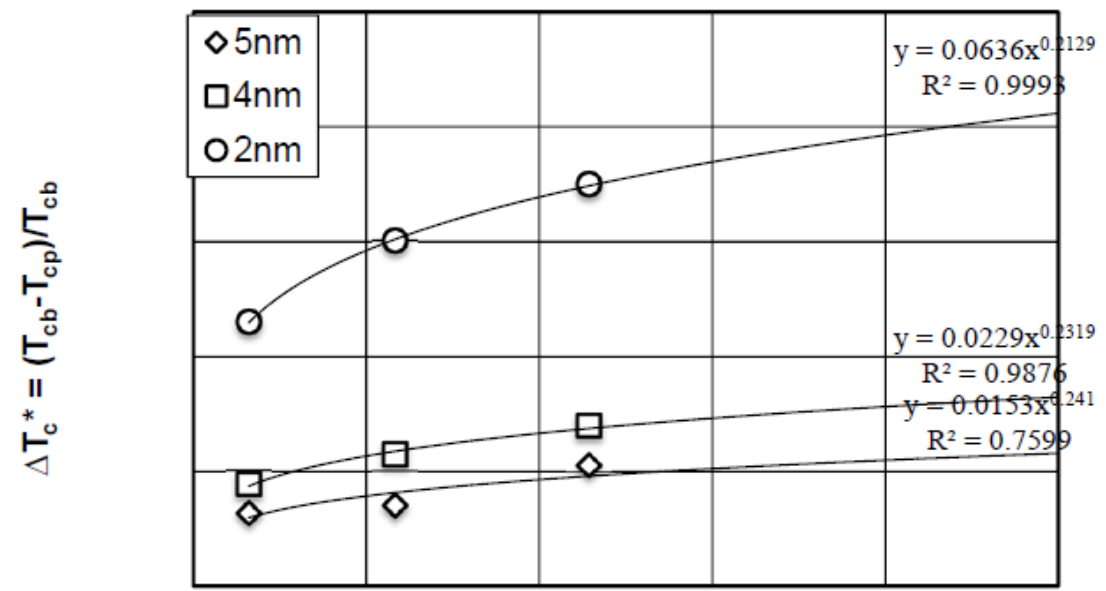

Molecular Weight

Figure 2-3 Relative deviation of critical temperature (Devegowda, 2012). 


\section{Chapter 3 Methodology}

The estimation of hydrocarbons-in-place can be completed by use of either the material balance method or the volumetric method. For this project, the volumetric method will be used. The volumetric method consists of approximating the volume of the reservoir and then estimating how much hydrocarbon is in that volume. For this study, the hydrocarbons will be estimated for a Marcellus Shale Reservoir. In the Marcellus Shale, the hydrocarbons are found in both an adsorbed form and as free gas. The free gas only exists in pore space so the volume of the pores is important for finding the volume of hydrocarbons. A simplified version of the volumetric method can be seen below:

$V_{b}($ Bulk Volume $)=A \times h=A r e a \times$ Height

$V_{p}($ Pore Volume $)=A \times h \times \emptyset=$ Area $\times$ Height $\times$ Porosity

$V_{H C}($ Hydrocarbon Volume $)=A \times h \times \emptyset \times S_{H C}=$ Area $\times$ Height $\times$ Porosity $\times$ Saturation of Hydrocarbons

$S_{H C}=S_{o}+S_{g}=$ Saturation of Oil + Saturation of Gas

$S_{H C}=1-S_{w i}=1-$ Irreducible Water Saturation

In equation 3.1 the bulk volume of the reservoir is found by multiplying the approximate area of the reservoir by the formation height. Equation 3.2 shows the pore volume equation, which includes the bulk volume multiplied by the porosity. Then, in equation 3.3, the hydrocarbon volume is calculated by multiplying the pore volume by the saturation of the hydrocarbons. The saturation of the hydrocarbons, shown in equation 
3.4 , is found by adding the saturation of oil to the saturation of gas or by using equation 3.5 and subtracting the irreducible water saturation from 1.

The focus of this study is on dry-gas reservoirs, but whether you are examining at oil or gas reservoirs, the hydrocarbon in place calculations depend on area, height, saturation, and porosity. For this study, the absorbed gas volume will be ignored.

The initial gas in place formula is shown below:

$G($ Initial Gas in Place $)=\frac{1.540 A h \phi\left(1-\overline{\left.S_{w l}\right)}\right.}{T_{f}}\left(\frac{p}{z}\right), M M C F$

$G=\frac{1.540 * V_{R^{*}} \overline{\bar{\phi} S_{g}}}{T_{f}}\left(\frac{p}{z}\right), M M C F$

In both equation 3.6 and $3.6, T_{f}$ is the formation temperature, $p$ is the formation pressure, and $\mathrm{z}$ is the $\mathrm{z}$-factor and $S_{H C}=S_{g}$. The factors like pressure, saturation, porosity, and temperature must be found by use of core samples, well log data, inferences and a combination of the three. To obtain height, porosity and water saturation, the data must be collected, then interpreted and then finally integrated. Saturation and porosity pose some difficulty in estimation because the reservoirs are heterogeneous. Table 3-1 shows the parameters that were used:

Table 3-1 Reservoir parameters used in the gas-in-place calculations.

\begin{tabular}{|c|c|c|}
\hline Variable & & Units \\
\hline Area (A) & 1 & acre \\
\hline height (h) & 1 & foot \\
\hline $\begin{array}{c}\text { porosity (Ø) } \\
\text { Irreducible Water } \\
\text { Saturation }\end{array}$ & 5 & $\%$ \\
\hline
\end{tabular}


Gas composition also plays a large role in the gas-in-place estimation because the composition effects the critical properties, like critical temperature and critical pressure, which in turn effects the gas compressibility. Table 3-2 shows the components of typical petroleum gases.

Table 3-2 Composition of typical petroleum gases (McCain, 1990).

\begin{tabular}{|c|c|}
\hline \multicolumn{2}{|c|}{$\begin{array}{c}\text { Components of Typical Petroleum Gases } \\
\text { Natural Gas }\end{array}$} \\
\hline Hydrocarbon & $70-98 \%$ \\
\hline Methane & $1-10 \%$ \\
\hline Ethane & Trace-5\% \\
\hline Propane & Trace-2\% \\
\hline Pentanes & Trace-1\% \\
\hline Hexanes & Trace-0.5\% \\
\hline Heptanes + & Trace-0.5\% \\
\hline Nonhydrocarbon & Trace-15\% \\
\hline Nitrogen & Trace-5\% \\
\hline Carbon dioxide & Up to 5\% $\%$ \\
\hline Helium & \\
\hline
\end{tabular}

Two gas compositions for two different areas of the Marcellus Shale will be compared. The first composition is from a compositions analysis of the separator gas in the Mary Field of Wetzel County, West Virginia. The second composition's exact location is unknown because the company that drilled the well did not want to disclose it, but the approximate location is the 
Marcellus Shale in Pennsylvania. The comparisons will show how the gas composition effects the gas-in-place. The following compositional data was used in this study:

Table 3-3 Study \#1 included separator gas compositional analysis from gas produced in the Marcellus Shale.

\begin{tabular}{|c|c|c|c|c|}
\hline \multicolumn{5}{|c|}{ Compositional Analysis of Separator Gas } \\
\hline \multicolumn{5}{|c|}{ Sample Date and Time: March 5, 2014 at 1620 hours } \\
\hline \multicolumn{5}{|c|}{ Sampling Conditions: $685 p s i a$ at $77^{\circ} \mathrm{F}$} \\
\hline \multicolumn{5}{|c|}{ Opening Conditions: 788 psia at $120^{\circ} \mathrm{F}$} \\
\hline Component & Mole \% & $\begin{array}{c}\text { GPM at } 14.85 \\
\text { psia }\end{array}$ & Weight \% & Molecular Weight \\
\hline $\begin{array}{c}\mathrm{CO}_{2} \text { (Carbon } \\
\text { Dioxide) }\end{array}$ & 0.156 & 0.00000 & 0.62800 & 44.01000 \\
\hline $\mathrm{N}_{2}$ (Nitrogen Gas) & 0.465 & 0.00000 & 0.33000 & 28.01300 \\
\hline $\begin{array}{c}\mathrm{H}_{2} \mathrm{~S} \text { (Hydrogen } \\
\text { Sulfide) }\end{array}$ & 0 & 0.00000 & 0.00000 & 34.08200 \\
\hline $\mathrm{CH}_{4}$ (Methane) & 77.299 & 0.00000 & 59.77100 & 16.04300 \\
\hline $\mathrm{C}_{2} \mathrm{H}_{6}($ Ethane) & 14.775 & 3.97600 & 21.41200 & 30.07000 \\
\hline $\mathrm{C}_{3} \mathrm{H}_{8}$ (Propane) & 4.885 & 1.35700 & 10.38200 & 44.09700 \\
\hline $\mathrm{i}^{-} \mathrm{C}_{4} \mathrm{H}_{10}$ (Isobutane) & 0.573 & 0.18900 & 1.60400 & 58.12300 \\
\hline$n-C_{4} H_{10}$ (Butane) & 1.156 & 0.36800 & 3.23900 & 58.12300 \\
\hline $\begin{array}{c}i-\mathrm{C}_{5} \mathrm{H}_{12} \\
\text { (Isopentane) }\end{array}$ & 0.239 & 0.08800 & 0.83200 & 72.15000 \\
\hline $\begin{array}{c}n-\mathrm{C}_{5} \mathrm{H}_{12} \\
\text { (Neopentane) }\end{array}$ & 0.23 & 0.08400 & 0.80100 & 72.15000 \\
\hline $\mathrm{C}_{6} \mathrm{H}_{14}$ (Hexane) & 0.129 & 0.05400 & 0.53500 & 86.17700 \\
\hline$C_{7}$ (Heptanes) & 0.053 & 0.02300 & 0.24800 & 96.68200 \\
\hline$C_{8}$ (Octanes) & 0.027 & 0.01200 & 0.13700 & 107.16300 \\
\hline$C_{9}$ (Nonanes) & 0.006 & 0.00300 & 0.03700 & 120.09000 \\
\hline $\begin{array}{c}C_{10}+\text { (Decanes } \\
\text { Plus) }\end{array}$ & 0.007 & 0.00400 & 0.04400 & 136.61400 \\
\hline
\end{tabular}


Table 3-4 Compositional data used in Study \#2.

\begin{tabular}{|c|c|}
\hline Component & Mole Fraction \\
\hline $\mathrm{CO}_{2}$ (Carbon Dioxide) & 0.00089 \\
\hline $\mathrm{N}_{2}$ (Nitrogen Gas) & 0.00354 \\
\hline $\mathrm{H}_{2} \mathrm{~S}$ (Hydrogen Sulfide) & 0.00000 \\
\hline $\mathrm{CH}_{4}$ (Methane) & 0.74305 \\
\hline $\mathrm{C}_{2} \mathrm{H}_{6}$ (Ethane) & 0.15185 \\
\hline $\mathrm{C}_{3} \mathrm{H}_{8}$ (Propane) & 0.05874 \\
\hline$i-C_{4} H_{10}$ (Isobutane) & 0.00713 \\
\hline$n-C_{4} H_{10}($ Butane $)$ & 0.01717 \\
\hline$i-C_{5} H_{12}$ (Isopentane) & 0.00370 \\
\hline$n-C_{5} H_{12}$ (Neopentane) & 0.00537 \\
\hline $\mathrm{C}_{6} \mathrm{H}_{14}$ (Hexane) & 0.00500 \\
\hline$C_{7}+$ & 0.00351 \\
\hline M.W. $C_{7}+$ & 136.00000 \\
\hline
\end{tabular}

The gas compositions then must be corrected for mole fractions because not all of the components are found in each sample. The corrected compositions are shown below: 
Table 3-5: Corrected compositions for Study \#1 for mole fractions.

\begin{tabular}{|c|c|c|}
\hline Component & Mole Fraction & Corrected Mole Frac. \\
\hline CO2(Carbon Dioxide) & 0.00156 & 0.00156 \\
\hline N2 (Nitrogen Gas) & 0.00465 & 0.00465 \\
\hline H2S(Hydrogen Sulfide) & 0.00000 & 0.00000 \\
\hline CH4 (Methane) & 0.77299 & 0.77299 \\
\hline C2H6(Ethane) & 0.14775 & 0.14775 \\
\hline C3H8 (Propane) & 0.04885 & 0.04885 \\
\hline i-C4H10 (Isobutane) & 0.00573 & 0.00573 \\
\hline$n-C 4 H 10$ (Butane) & 0.01156 & 0.01156 \\
\hline i-C5H12 (Isopentane) & 0.00239 & 0.00239 \\
\hline$n-C 5 H 12$ (Neopentane) & 0.00230 & 0.00230 \\
\hline C6H14 (Hexane) & 0.00129 & 0.00129 \\
\hline C7+ & 0.00093 & 0.00093 \\
\hline
\end{tabular}

Table 3-6: Corrected compositions for Study \#2 for mole fractions.

\begin{tabular}{|c|c|c|}
\hline Component & Mole Fraction & Corrected Mole Frac. \\
\hline CO2(Carbon Dioxide) & 0.00089 & 0.00089 \\
\hline N2 (Nitrogen Gas) & 0.00354 & 0.00355 \\
\hline H2S(Hydrogen Sulfide) & 0.00000 & 0.00000 \\
\hline CH4 (Methane) & 0.74305 & 0.74308 \\
\hline C2H6(Ethane) & 0.15185 & 0.15185 \\
\hline C3H8 (Propane) & 0.05874 & 0.05874 \\
\hline i-C4H10 (Isobutane) & 0.00713 & 0.00714 \\
\hline$n-C 4 H 10($ Butane) & 0.01717 & 0.01717 \\
\hline$i-C 5 H 12$ (Isopentane) & 0.00370 & 0.00370 \\
\hline$n-C 5 H 12$ (Neopentane) & 0.00537 & 0.00537 \\
\hline C6H14 (Hexane) & 0.00500 & 0.00500 \\
\hline C7+ & 0.00351 & 0.00351 \\
\hline
\end{tabular}


The corrections shown in Table 3-4 and 3.5 are performed to because the data for composition \#1 includes Heptanes, Octanes, Nonanes, Decanes Plus, whereas the composition \#2 data includes only up to $\mathrm{C} 7+$. To make the data sets comparable the mole fractions were adjusted. Once the corrected compositional data is obtained, the next step is to assess the critical temperature and pressure for the unconfined pore size (10$100 \mathrm{~nm}), 2 \mathrm{~nm}$ pore size, $4 \mathrm{~nm}$ pore size, and $5 \mathrm{~nm}$ pore size. Please see appendix A for the critical temperature and pressure results. The correlations for the critical temperature and pressure due to confinement were found using the correlations by Deepak illustrated in the following Figures:

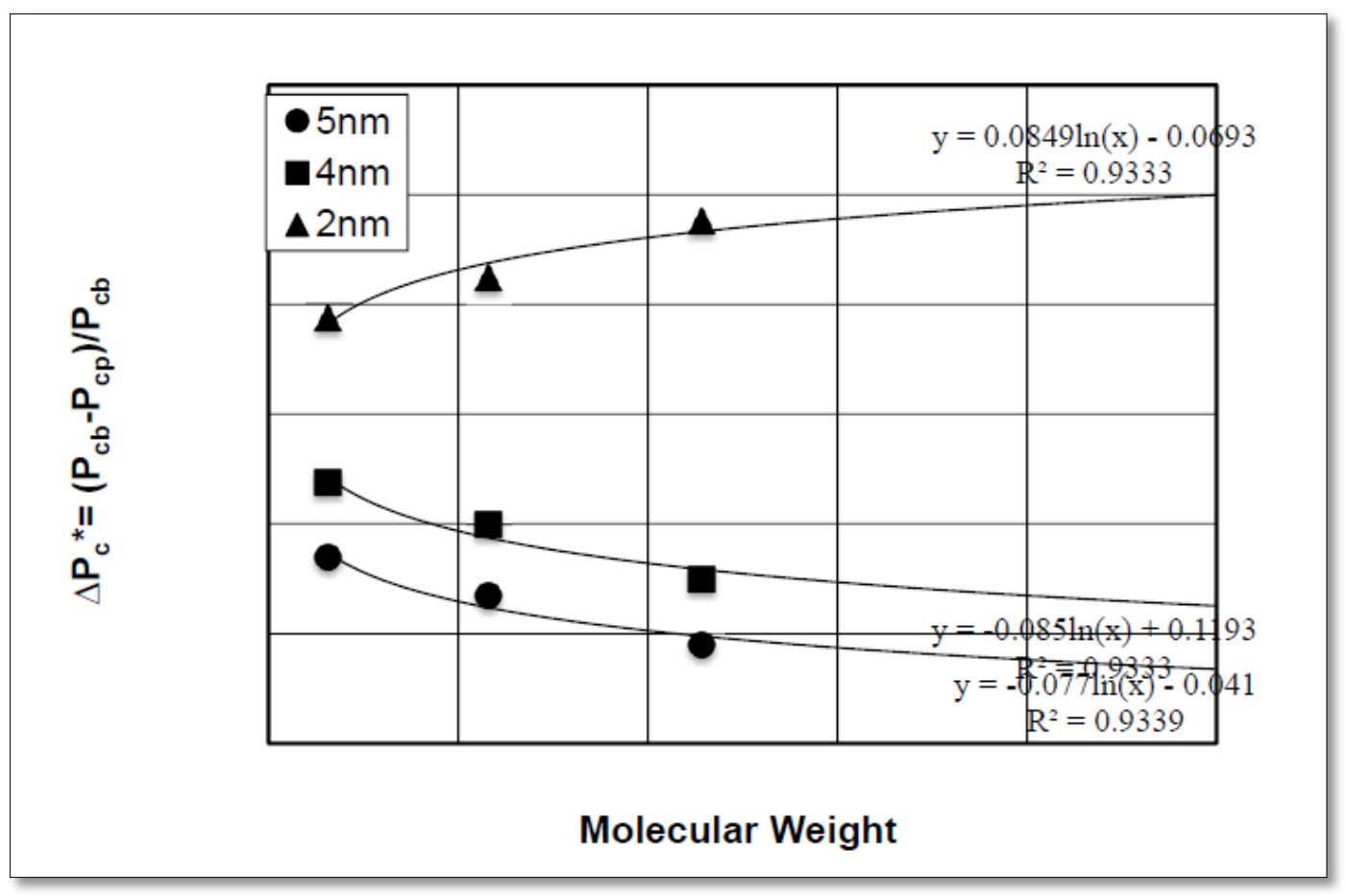

Figure 3-1: Critical Pressure Correlation for Molecular Weight (Devegowda, 2012). 


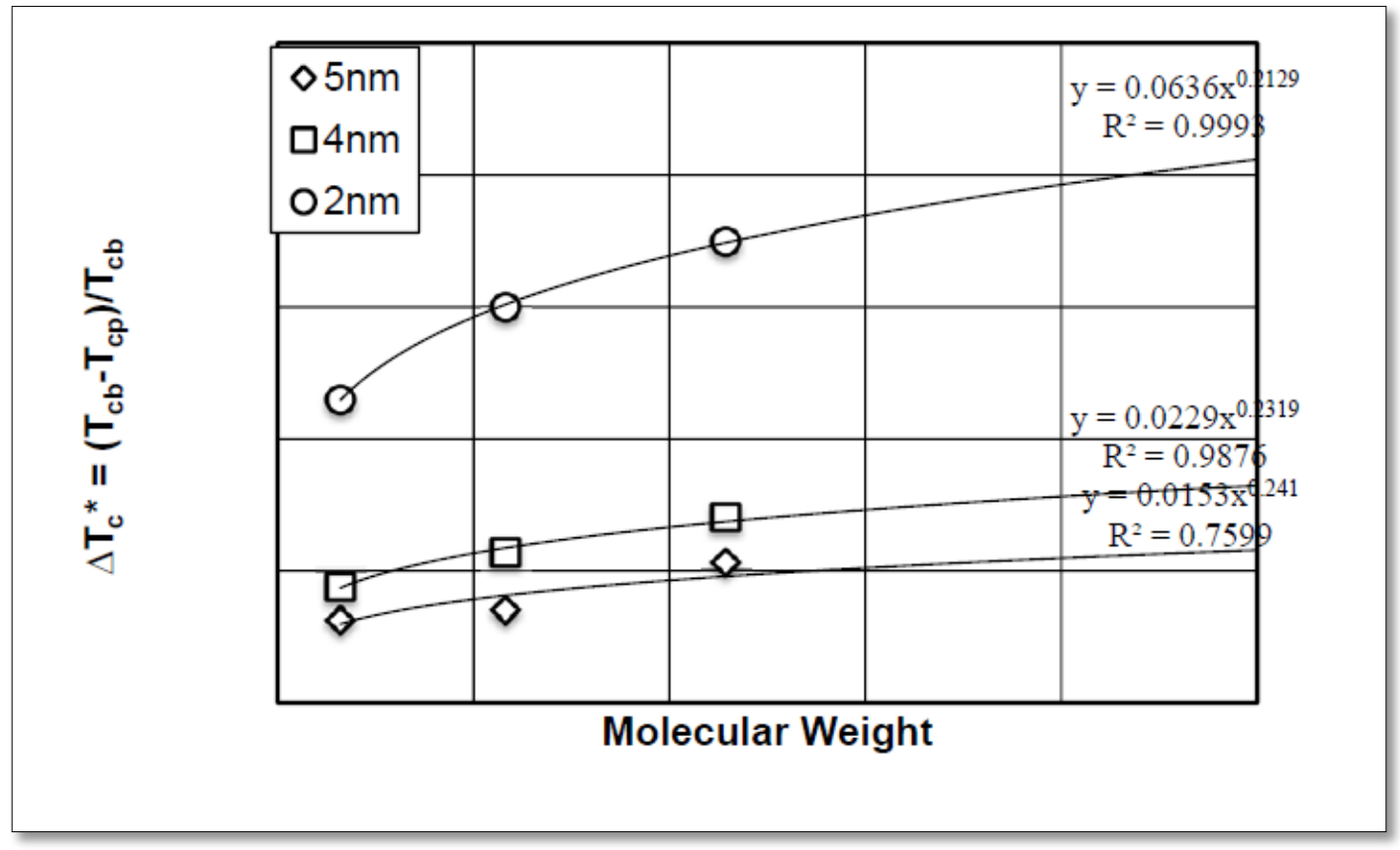

Figure 3-2: Critical Temperature Correlation for Molecular Weight (Devegowda, 2012).

Where $P_{c p}$ and $T_{c p}$ are the critical pressure and temperature in confined pores and $P_{c b}$ and $T_{c b}$ are the corresponding values in bulk. The results of the temperature and pressure correlations are shown in Appendix A. Next, the summated critical temperature and pressure are found. To find the summated critical pressure, the corrected mole fraction for each component is multiplied by the correlated critical pressure of each component. These multiplied results are then added together, which is why the result is called the summated critical pressure but it essentially representative of a weighted average. To find the summated critical temperature the corrected mole fraction for each component is multiplied by the correlated critical temperature of each component. These multiplied results are then added together. Then the summated critical temperature (in Rankin) and pressure (in psia) are adjusted by the formation temperature and pressure to get the pseudo reduced temperature and pressure respectively. The pseudo reduced 
temperature and pressure are used on the compressibility chart or z-factor chart. This chart is shown in appendix A.

Once the z-factors are found for each condition they are applied to the gas-in-place calculation. The formation pressure and temperature for the Marcellus Shale are usually between $3000-4000$ psia and $115-135^{\circ} \mathrm{F}$. The same methodology for each of the pore sizes was completed for each of the following formation temperatures and pressures:

Table 3-7 Formation pressures and temperatures used for both of the compositions.

\begin{tabular}{|c|c|}
\hline $\begin{array}{c}\text { Formation } \\
\text { Pressure } \\
(\text { psia })\end{array}$ & $\begin{array}{c}\text { Formation } \\
\text { Temperature } \\
\left({ }^{\circ} \mathrm{F}\right)\end{array}$ \\
\hline 3000 & 115 \\
\hline 3100 & 117 \\
\hline 3200 & 119 \\
\hline 3300 & 121 \\
\hline 3400 & 123 \\
\hline 3500 & 125 \\
\hline 3600 & 127 \\
\hline 3700 & 129 \\
\hline 3800 & 130 \\
\hline 3900 & 133 \\
\hline 4000 & 135 \\
\hline
\end{tabular}

Using these 11 pressure and temperature conditions plus the 4 pore size conditions and the two different compositions there will be about 88 scenarios for comparison for the Marcellus Shale. These comparisons will be shown in the results section. 


\section{Chapter 4 Results and Discussion}

This section describes the results of the study on the size effects of the nanopores on the gas-inplace calculation. It is important to compare the results of the different Marcellus Shale regions to see the effects that the depths of the reservoir have and also the compositions. The organization of these results are most simply shown in the figure below:

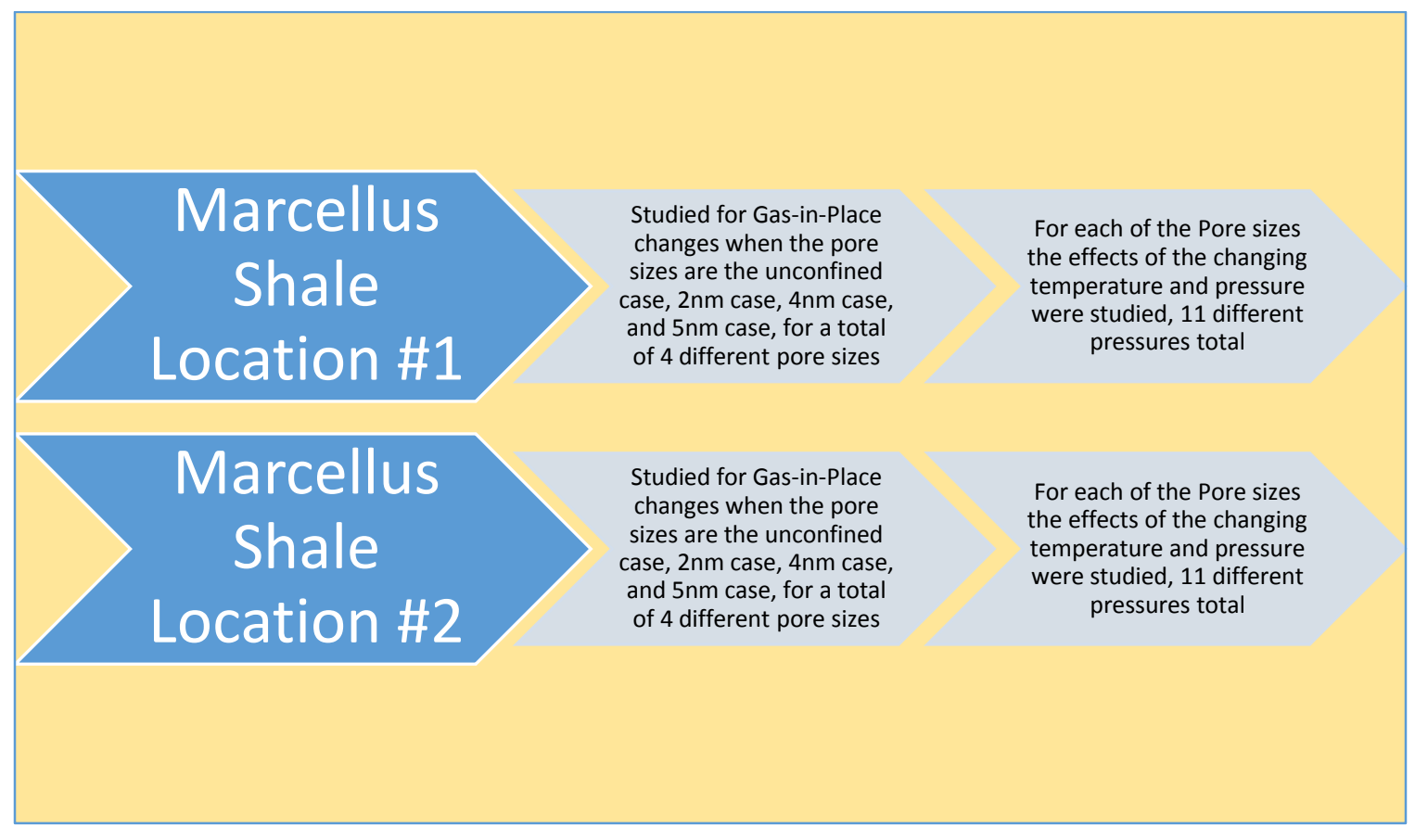

Figure 4-1 Flow chart and organization for the study of nanopore effects on gas-inplace.

\subsection{Nanopore Size Effects on the Pseudo Reduced Temperatures and Pressures}

The formation temperature for each of the locations was studied for the pore size effects and formation pressure effects when the temperature changes from 115-135 degrees Fahrenheit and from 3000 psia to 4000 psia formation pressure. These formation temperatures were then used to calculate the effects on the pseudo reduced pressure of the two different gas compositions of the two Marcellus Shale locations. 


\section{Pore Size Effects on Pseudo Reduced}

Temperature

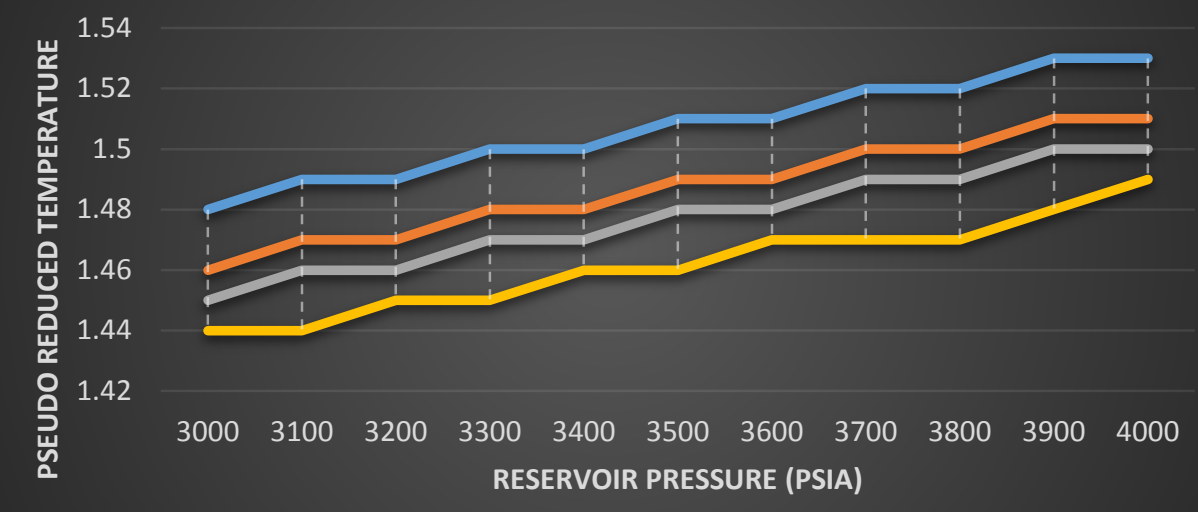

Reduced Temp 2nm Reduced Temp 4 nm

$\longrightarrow$ Reduced Temp 5nm $\longrightarrow$ Reduced Temp Unconfined

Figure 4-2 Study \#1 Pseudo reduced temperature results for the changing reservoir pressures.

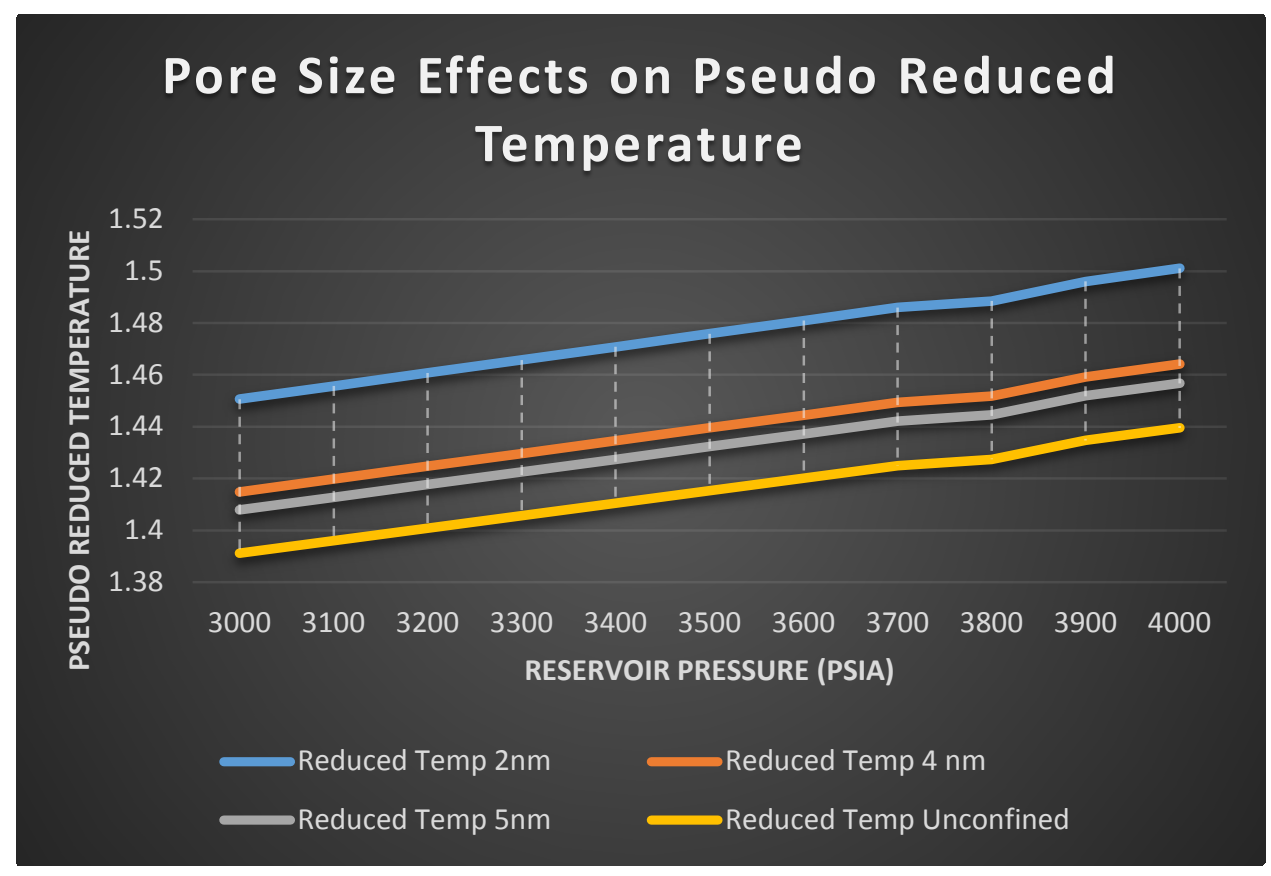

Figure 4-3 Study \#2 Pseudo reduced temperature results for the changing reservoir pressures. 
The conclusion is made that the higher the formation temperature the higher the pseudo reduced pressure will be because of the calculation for the pseudo reduced pressure which is shown below:

$$
\text { Pseudo Reduced Temperature }=\frac{\text { Formation Temperature }\left({ }^{\circ} \mathrm{R}\right)}{\text { Critical Temperature }}
$$

The pore size shows that the pseudo reduced temperature increases with the reduction in pore size. This is due to the increases in pressure on the hydrocarbons that occurs in a confined space. Although, the results from the two compositions are slightly different, they follow the same trend.

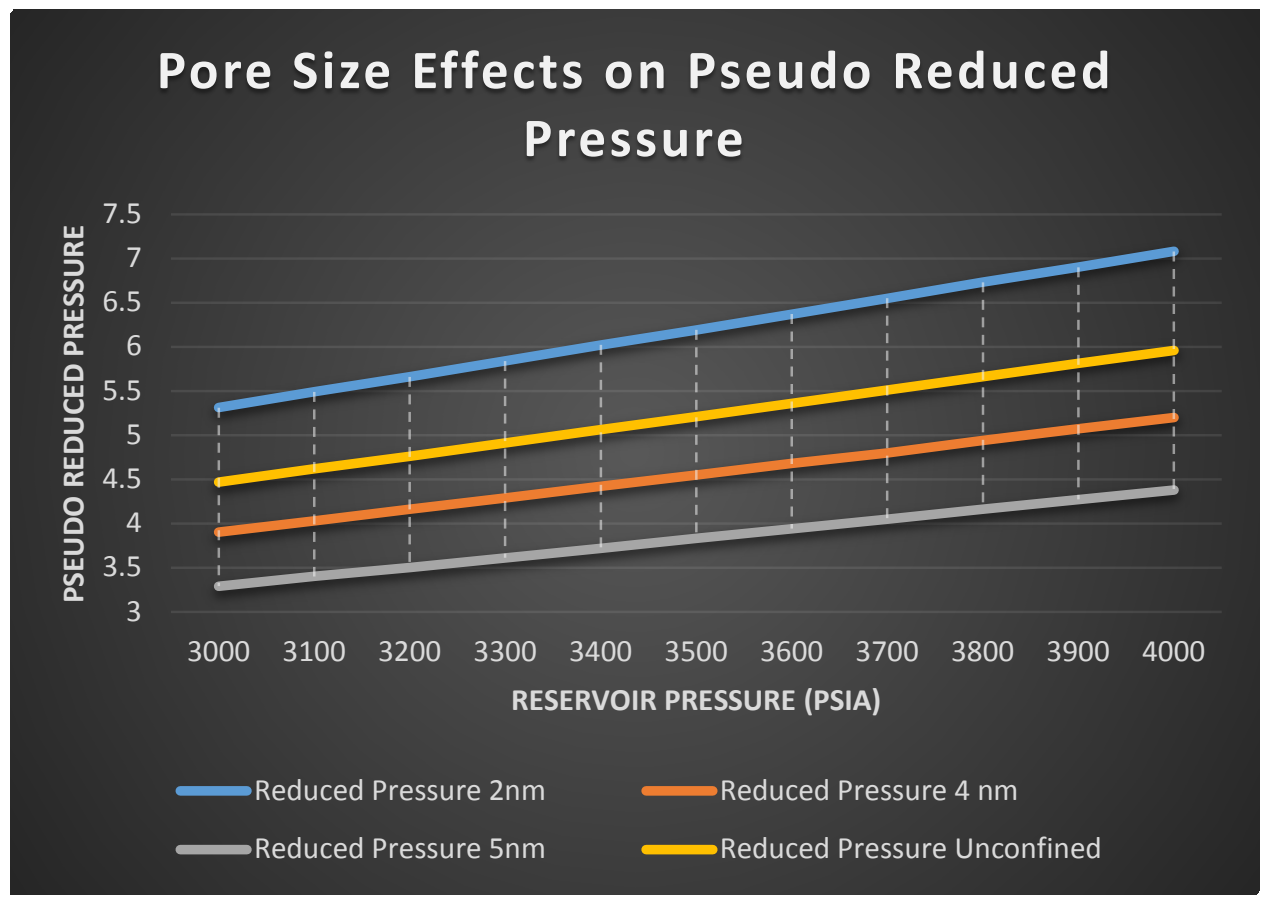

Figure 4-4 Study \#1 Pseudo reduced pressure results for the changing reservoir pressures and pore sizes. 


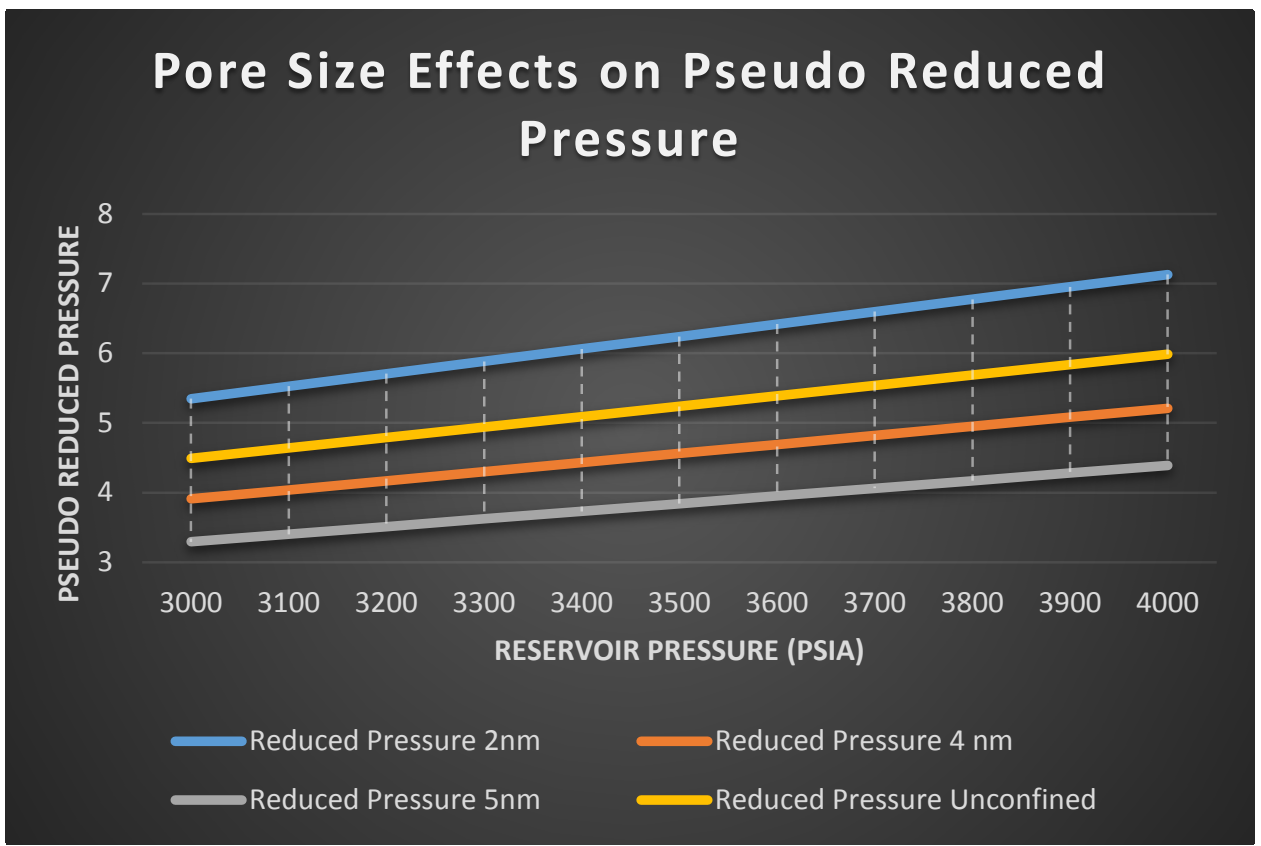

Figure 4-5 Study \#2 Pseudo reduced pressure results for the changing reservoir pressures and pore sizes.

The pseudo reduced pressure shows a trend that is different from the pseudo reduced temperature. The pseudo-reduced pressure still has the trend of the pressure increasing with the increased reservoir pressure but the pore size does not follow the same trend as the pseudoreduced temperature. The $2 \mathrm{~nm}$ pore size has the highest pseudo-reduced pressure, the unconfined pore size has the next highest pseudo-reduced pressure, the $4 \mathrm{~nm}$ has the next highest and the $5 \mathrm{~nm}$ pore size has the lowest pseudo reduced pressure. Comparing the two compositions from the two different locations there is almost no difference in the pseudo-reduced pressure.

\subsection{Pore Size Effects on Compressibility and Gas-in-Place}

When calculating the compressibility of a gas there are many ways to do so. The method that was chosen uses the critical temperature and pressure in the calculation because this allows the compressibility to show the changes in critical temperature and pressure with confinement effects. 
The z-factor calculation was explained in the methodology section. This section will present the results of the calculation and introduce the effects that confinement has had on the gas compressibility. In the chart below the pore size effects on compressibility are plotted with a changing reservoir pressure for four different pore sizes: unconfined, $2 \mathrm{~nm}, 4 \mathrm{~nm}$ and $5 \mathrm{~nm}$.

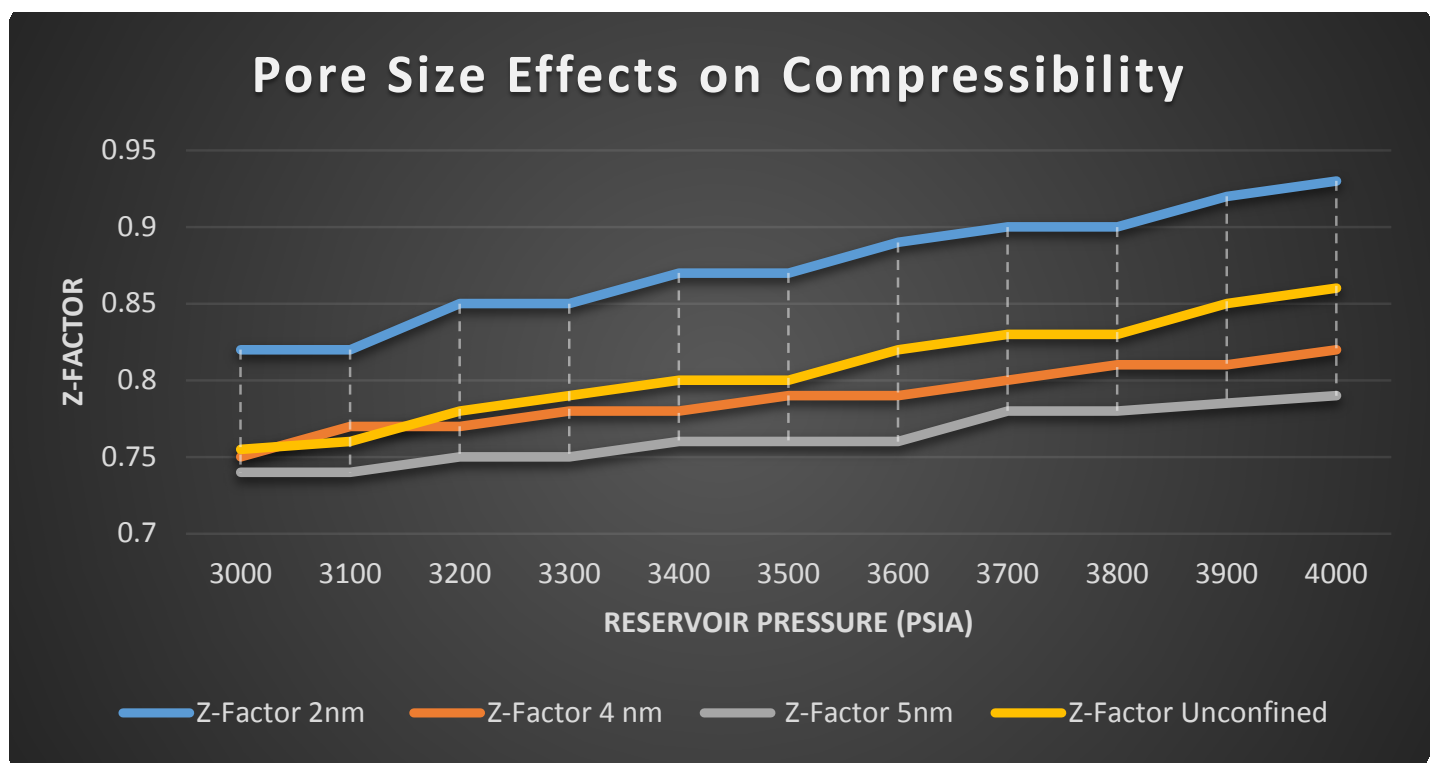

Figure 4-6 Study \#1 Compressibility results for the changing reservoir pressures and pore sizes.

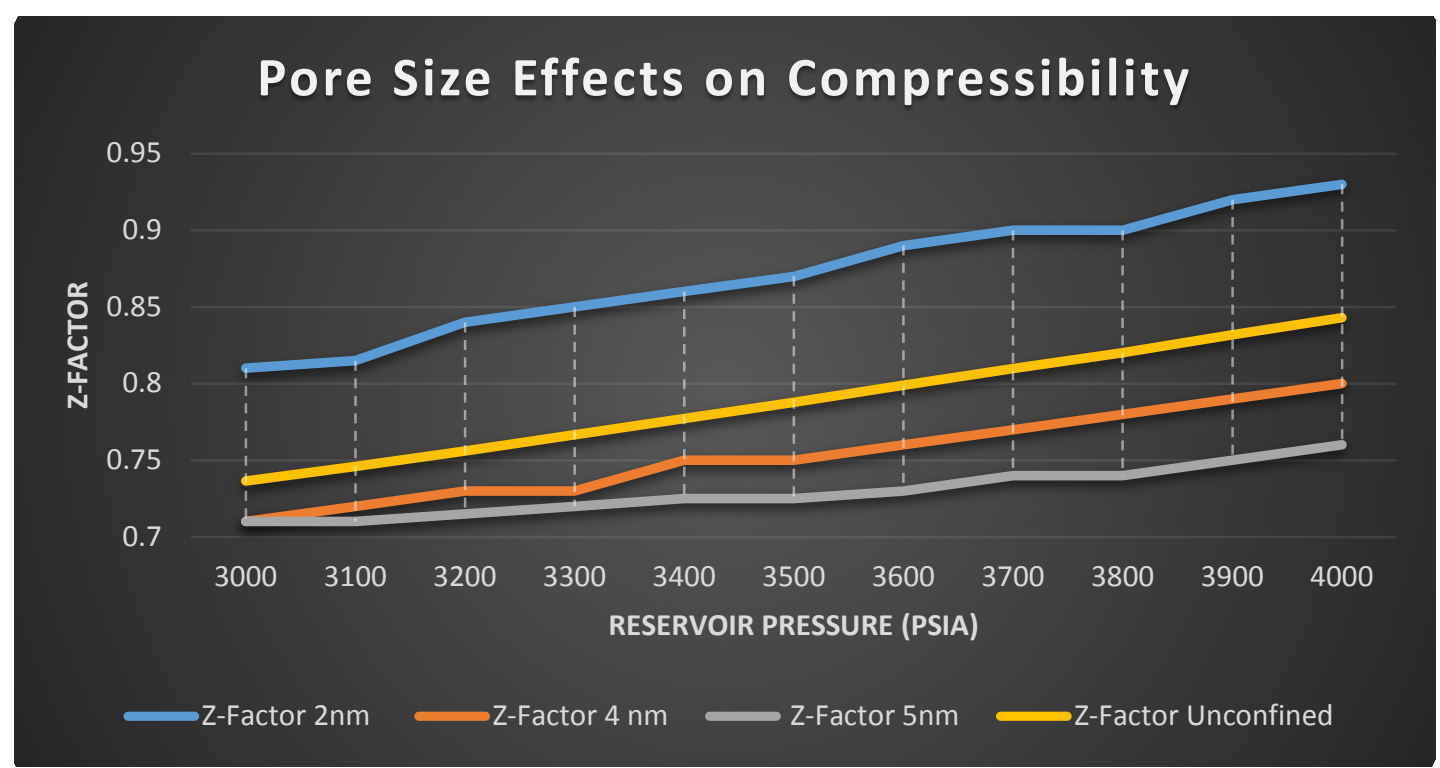

Figure 4-7 Study \#2 Compressibility results for the changing reservoir pressures and pore sizes. 
The pore size of $5 \mathrm{~nm}$ has the lowest gas compressibility and the $2 \mathrm{~nm}$ pore size has the highest compressibility. The $4 \mathrm{~nm}$ pore size is the second lowest with the unconfined pore size only slightly above it. The effects on the compressibility for the changing compositions is almost nothing.

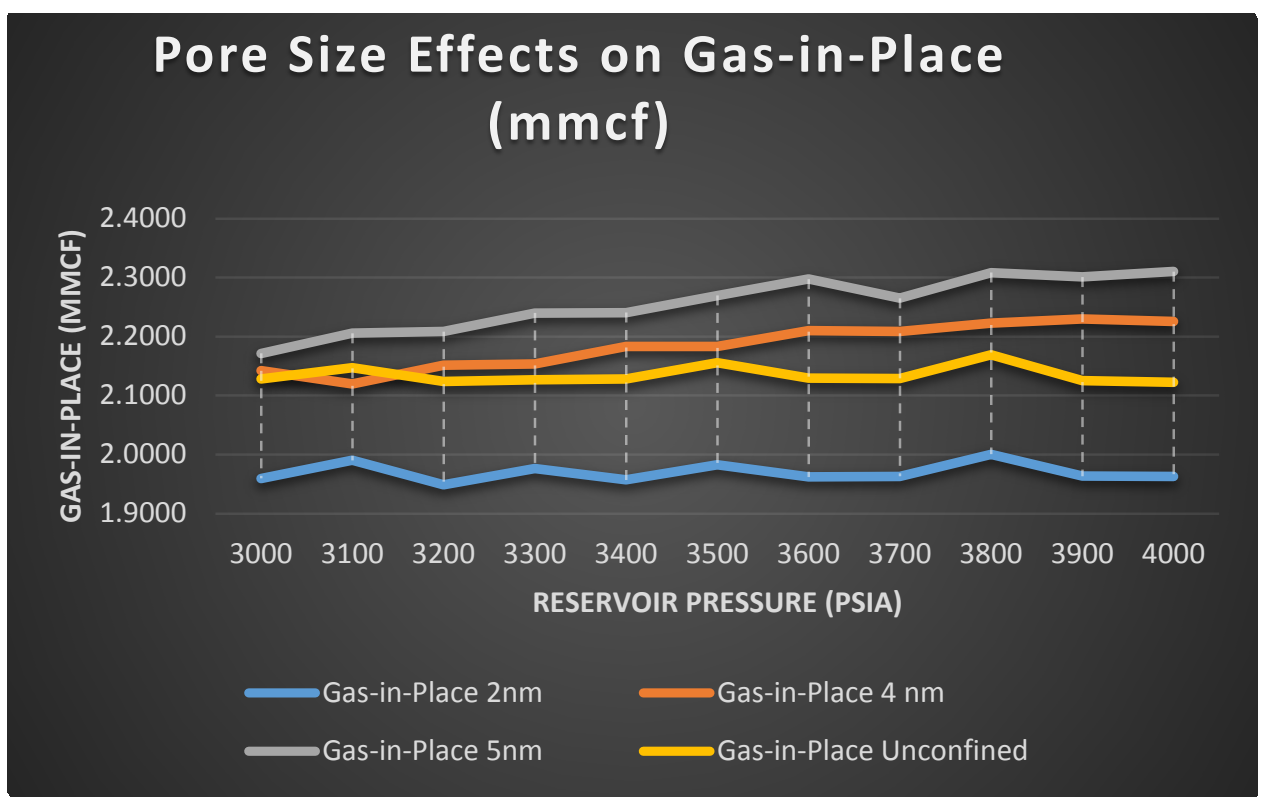

Figure 4-8 Study \#1 gas-in-place results for the changing reservoir pressures and pore sizes.

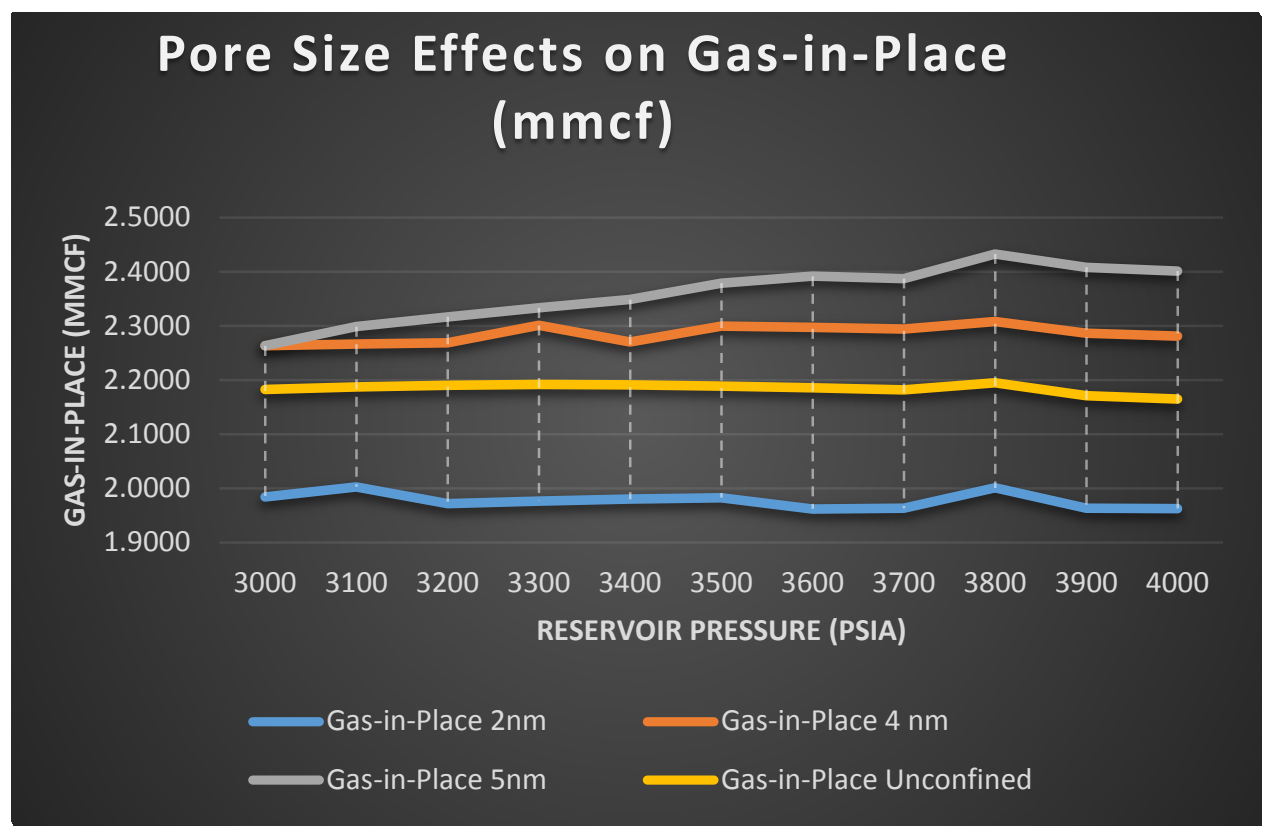

Figure 4-9 Study \#2 gas-in-place results for the changing reservoir pressures and pore sizes. 
The gas-in-place is effected most by the $5 \mathrm{~nm}$ pore size and the $2 \mathrm{~nm}$ pore size. The $4 \mathrm{~nm}$ pore size behaves closely to the unconfined pore size. The changing pore sizes compared to the changing compositions are shown in the tables below:

Table 4-1 Percent change of the gas-in-place comparing the composition \#1 and \#2 when increasing the formation pressure from 3000 psia to 4000 psia.

\begin{tabular}{|c|c|c|c|c|c|c|c|}
\hline \multicolumn{8}{|c|}{ Percent Change of Gas-in-Place from 3000 to 4000 psia } \\
\hline \multicolumn{4}{|c|}{ Composition \#1 (lighter gas) } & \multicolumn{4}{|c|}{ Composition \#2 (heavier gas) } \\
\hline \multicolumn{4}{|c|}{ Gas-in-Place } & \multicolumn{4}{|c|}{ Gas-in-Place } \\
\hline $2 \mathrm{~nm}$ & $4 \mathrm{~nm}$ & $5 \mathrm{~nm}$ & unconfined & $2 \mathrm{~nm}$ & $4 \mathrm{~nm}$ & $5 \mathrm{~nm}$ & Unconfined \\
\hline $0.146 \%$ & $3.739 \%$ & $6.008 \%$ & $-0.288 \%$ & $-1.087 \%$ & $0.796 \%$ & $5.756 \%$ & $-0.787 \%$ \\
\hline
\end{tabular}

As the pressure increases from 3000 psia to 4000 psia the lighter gas shows an increase in gasin-place (excluding the unconfined pore size which shows almost no change). The heavier gas does not follow the same trend, the $2 \mathrm{~nm}$ pore size, $4 \mathrm{~nm}$ pore size and unconfined case show almost no change to in gas-in-place as the pressure increases but the $5 \mathrm{~nm}$ pore size shows a $5 \%$ increase in gas-in-place as the reservoir pressure increases from 3000 psia to 4000 psia.

Table 4-2 Percent change of gas-in-place between composition \#1 and \#2.

\begin{tabular}{|c|c|c|c|c|c|}
\hline \multicolumn{5}{|c|}{ Percent Change of Gas-in-Place Between the Changing Compositions } \\
\hline Temperature & Pressure & $\mathbf{2}$ nm & 4 nm & 5 nm & unconfined \\
\hline 115 & 3000 & $1 \%$ & $5 \%$ & $4 \%$ & $2 \%$ \\
\hline 117 & 3100 & $1 \%$ & $6 \%$ & $4 \%$ & $2 \%$ \\
\hline 119 & 3200 & $1 \%$ & $5 \%$ & $5 \%$ & $3 \%$ \\
\hline 121 & 3300 & $0 \%$ & $6 \%$ & $4 \%$ & $3 \%$ \\
\hline 123 & 3400 & $1 \%$ & $4 \%$ & $5 \%$ & $3 \%$ \\
\hline 125 & 3500 & $0 \%$ & $5 \%$ & $5 \%$ & $2 \%$ \\
\hline 127 & 3600 & $0 \%$ & $4 \%$ & $4 \%$ & $3 \%$ \\
\hline 129 & 3700 & $0 \%$ & $4 \%$ & $5 \%$ & $2 \%$ \\
\hline 130 & 3800 & $0 \%$ & $4 \%$ & $5 \%$ & $1 \%$ \\
\hline 135 & 3900 & $0 \%$ & $2 \%$ & $4 \%$ & $2 \%$ \\
\hline
\end{tabular}


When comparing the change in the gas-in-place when the compositions change, the heavier gas shows an increase in gas-in-place which is why the percentages in the above table are positive. The $4 \mathrm{~nm}$ and $5 \mathrm{~nm}$ pore sizes exhibit a higher change of gas-in-place than the $2 \mathrm{~nm}$ and unconfined cases. Lastly, the comparison of the gas-in-place for each composition for each pore size is shown in the table below:

Table 4-3 Comparison of the changes to the gas-in-place for the changing composition and pore size.

\begin{tabular}{|c|c|c|c|c|c|c|c|}
\hline \multicolumn{8}{|c|}{$\%$ Change of Gas in Place for the Change in Pore Size } \\
\hline \multirow{2}{*}{$\begin{array}{c}\text { Temperature } \\
115\end{array}$} & \multirow{2}{*}{$\begin{array}{c}\text { Pressure } \\
\mathbf{3 0 0 0}\end{array}$} & \multicolumn{3}{|c|}{ Composition \#1 (lighter gas) } & \multicolumn{3}{|c|}{ Composition \#2 (heavier gas) } \\
\hline & & $2 n m$ & $4 \mathrm{~nm}$ & $5 \mathrm{~nm}$ & $2 n m$ & $4 \mathrm{~nm}$ & $5 n m$ \\
\hline 117 & 3100 & $-9 \%$ & $1 \%$ & $2 \%$ & $-10 \%$ & $4 \%$ & $4 \%$ \\
\hline 119 & 3200 & $-8 \%$ & $-1 \%$ & $3 \%$ & $-9 \%$ & $3 \%$ & $5 \%$ \\
\hline 121 & 3300 & $-9 \%$ & $1 \%$ & $4 \%$ & $-11 \%$ & $3 \%$ & $5 \%$ \\
\hline 123 & 3400 & $-8 \%$ & $1 \%$ & $5 \%$ & $-11 \%$ & $5 \%$ & $6 \%$ \\
\hline 125 & 3500 & $-9 \%$ & $2 \%$ & $5 \%$ & $-11 \%$ & $3 \%$ & $7 \%$ \\
\hline 127 & 3600 & $-9 \%$ & $1 \%$ & $5 \%$ & $-10 \%$ & $5 \%$ & $8 \%$ \\
\hline 129 & 3700 & $-9 \%$ & $4 \%$ & $7 \%$ & $-11 \%$ & $5 \%$ & $9 \%$ \\
\hline 130 & 3800 & $-8 \%$ & $4 \%$ & $6 \%$ & $-11 \%$ & $5 \%$ & $9 \%$ \\
\hline 133 & 3900 & $-8 \%$ & $2 \%$ & $6 \%$ & $-10 \%$ & $5 \%$ & $10 \%$ \\
\hline \multirow[t]{2}{*}{135} & 4000 & $-8 \%$ & $5 \%$ & $8 \%$ & $-11 \%$ & $5 \%$ & $10 \%$ \\
\hline & & $-8 \%$ & $5 \%$ & $8 \%$ & $-10 \%$ & $5 \%$ & $10 \%$ \\
\hline
\end{tabular}

The change of the gas-in-place for the lighter gas shows that there is a about a $9 \%$ decrease in the $2 \mathrm{~nm}$ pore size but in the $4 \mathrm{~nm}$ there is almost no change and in the $5 \mathrm{~nm}$ pore size there is up to a $7 \%$ increase. For the heavier gas there is about a $10 \%$ increase in the gas-in-place in the $2 \mathrm{~nm}$ pore size but the $4 \mathrm{~nm}$ and $5 \mathrm{~nm}$ pore sizes shown about a $6 \%$ decrease. 


\section{Chapter 5 Conclusion}

The objective of this study was to decide if the nanopores found in the Marcellus Shale have an impact on the gas-in-place calculation. To perform the study the unconfined pore formula for gasin-place was compared to the formula accounting for pore size.

In summary, the results of this study have shown that confined pores do have an effect on the gas-in-place estimates. The greatest effects are seen in the $5 \mathrm{~nm}$ pore size and the $2 \mathrm{~nm}$ pore size. The gas-in-place shows up to an $-8 \%$ change for the $2 \mathrm{~nm}$ pore size when compared to the unconfined case.

Table 5-1 Percent change of the gas-in-place found in the Marcellus Shale from the unconfined pore size condition.

\begin{tabular}{|c|c|c|c|}
\hline \multicolumn{3}{|c|}{ Gas-in-Place Results } & $\begin{array}{c}\text { \% Change } \\
\text { from } \\
\text { Unconfined }\end{array}$ \\
\hline \multirow{3}{*}{ G (MMCF) } & 2.001 & for $2 \mathrm{~nm}$ & $-8 \%$ \\
\cline { 2 - 4 } & 2.223 & for $4 \mathrm{~nm}$ & $2 \%$ \\
\cline { 2 - 4 } & 2.308 & for $5 \mathrm{~nm}$ & $6 \%$ \\
\cline { 2 - 4 } & 2.169 & for Normal & \\
\hline
\end{tabular}

These are the recommendations for future work:

1. Further work should be done to improve this study like adding an absorption factor to the gas-in-place formula.

2. This work could also be expanded if more pore sizes were included and more compositions from different shales.

3. There could also be an enhancement made on the formula to account for many different sized pores. 


\section{References}

Bustin, R. M., Bustin, A. M., Cui, X., Ross, S. C., \& Pathy, M. (2008). Impact of Shale Properties on Pore Structure and Storage Characteristics. SPE Shale Gas Production Conference (p. 28). Fort Worth: Society of Petroleum Engineers.

Ambrose, R., Hartman, R., \& Akkutlu, Y. (2011). Multi-Component Sorbed-Phase Considerations for Shale Gas-in-Place. Society of Petroleum Engineers .

Beliveau, D. (1993). Honey, I Shrunk the Pores! Journal of Canadian Petroleum Technology.

Bennion, D., \& Thomas, F. (1996). Formation Damage and Horizontal Wells-A Productivity Killer? International Conference on Horizontal Well Technology. Calgary: Society of Petroleum Engineers.

Beskok, A., \& Karniadakis, G. (1999). A Model for Flows in Channels, Pipes, and Ducts at Micro and Nano Scales. Microscale Thermophysical Engineering.

Curtis, J. (2002). Fractured Shale-Gas Systems. AAPG Bulletin , 86, 1921-1938.

Curtis, M. E., Ambrose, R. J., \& Sondergeld, C. R. (2010). Structural Characterization of Gas Shales on the Micro- and Nano-Scales. Canadian Unconventional Resource \& International Petroleum Conference (p. 15). Calgary: Society of Petroleum Engineers.

Devegowda, D., Sapmanee, K., Civan, F., \& Sigal, R. (2012). Phase Behavior of Gas Condensates in Shales Due to Pore Proximity Effects: Implications for Transport, Reserves and Well Productivity. SPE Annual Technical Conference and Exhibition. San Antonio: Society of Petroleum Engineers .

Javadpour, F., Fisher, D., \& Unsworth, M. (2007). Nano-Scale Gas Flow in Shale Sediments. Journal of Canadian Petroleum Technology , 46 (10), 55-61.

Jin, L., Ma, Y., \& Jamili, A. (2013). Investigating the Effect of Pore Proximity on Phase Behavior and Fluid Properties in Shale Formations. SPE Annual Technical Conference and Exhibition (p. 12). New Orleans: Society of Petroleum Engineers.

Ma, Y., Jin, L., \& Jamili, A. (2013). Modifying Van Der Waals Equation of State to Consider Influence of Confinement on Phase Behavior. SPE Annual Technical Conference and Exhibition. New Orleans: Society of Petroleum Engineers.

McCain, W. D. (1990). The Properties of Petroleum Fluids. Tulsa, Oklahoma: PennWell Books.

Michel, G. G. (2011). Parametric Investigation of Shale Gas Production Considering Nano-Scale Pore Size Distribution, Formation Factor, and Non-Darcy Flow Mechanisms. SPE Annual Technical Conference and Exhibition (p. 20). Denver: Society of Petroleum Engineers.

Reed, R. M., \& Wang, F. P. (2009). Pore Networks and Fluid Flow in Gas Shales. SPE Annual Technical Conference and Exhibition (p. 8). New Orleans: Society of Petroleum Engineers. 
Rezaveisi, M., Javadpour, F., \& Sepehrnoori, K. (2013). Modeling Chromatographic Separation of Produced Gas in Shale Wells. The University of Texas at Austin, Petroleum and Geosystems Engineering, Austin.

Rushing, J., Newsham, K., \& Fraassen, K. (2003). Measurement of the Two-Phase Gas Slippage Phenomenon and Its Effect on Gas Relative Permeability in Tight Gas Sands. SPE Annual Technical Conference and Exhibition. Society of Petroleum Engineers.

Singh, S., Sinha, A., Deo, G., \& Singh, J. (2009). Vapor-Liquid Phase Coexistence, Critical Properties, and Surface Tension of Confined Alkanes. J. Phys. Chem 113.

Sondergeld, C. H., Ambrose, R. J., \& Rai, C. S. (2010). Micro-Structural Studies of Gas Shales. SPE Unconventional Gas Conference (p. 17). Pittsburgh Society of Petroleum Engineers. 
Appendix A:

Table 1-A Study \#1 critical temperature and pressure for unconfined pores.

\begin{tabular}{|c|c|c|}
\hline Component & $\begin{array}{c}\text { Critical } \\
\text { Temperature, } \\
{ }^{\mathbf{R}}\end{array}$ & $\begin{array}{c}\text { Critical } \\
\text { Pressure, } \\
\text { psia }\end{array}$ \\
\hline CO2 (Carbon Dioxide) & 547.7 & 1073.0 \\
\hline N2 (Nitrogen Gas) & 227.0 & 493.0 \\
\hline H2S(Hydrogen Sulfide) & 672.0 & 1306.0 \\
\hline CH4 (Methane) & 343.3 & 673.1 \\
\hline C2H6 (Ethane) & 549.8 & 708.3 \\
\hline C3H8 (propane) & 666.0 & 617.4 \\
\hline $\boldsymbol{i}$-C4H10 (isobutane) & 734.7 & 529.1 \\
\hline n-C4H10 (butane) & 765.3 & 550.7 \\
\hline $\boldsymbol{i}$-C5H12 (isopentane) & 829.8 & 483.0 \\
\hline $\boldsymbol{n}$-C5H12 (neopentane) & 845.6 & 489.5 \\
\hline C6H14 (hexane) & 914.0 & 439.7 \\
\hline C7+ & 1070.3 & 369.6 \\
\hline
\end{tabular}


Table 2-A Study \#1 critical temperature and pressure correlation results for the $2 \mathrm{~nm}$ pore size.

\begin{tabular}{|c|c|c|}
\hline \multicolumn{3}{|c|}{$2 \mathrm{~nm}$ Pore Size Tc and Pc Correlation } \\
\hline Component & $T_{C},{ }^{o} R$ & $P_{c}, p s i a$ \\
\hline $\mathrm{CO}_{2}$ (Carbon Dioxide) & 985.9 & 854.5 \\
\hline $\mathbf{N}_{2 \text { (Nitrogen Gas) }}$ & 217.4 & 405.6 \\
\hline $\mathrm{H}_{2} \mathrm{~S}$ (Hydrogen Sulfide) & 1209.6 & 1306.0 \\
\hline $\mathrm{CH}_{4}$ (Methane) & 330.7 & 572.1 \\
\hline $\mathrm{C}_{2} \mathrm{H}_{6}$ (Ethane) & 525.5 & 580.8 \\
\hline $\mathrm{C}_{3} \mathrm{H}_{8 \text { (propane) }}$ & 696.3 & 491.7 \\
\hline$i-C_{4} H_{10}$ (iso-butane) & 725.5 & 432.0 \\
\hline$n-C_{4} H_{10}$ (butane) & 696.3 & 414.7 \\
\hline${ }_{i}-\mathrm{C}_{5} \mathrm{H}_{12}$ (isopentane) & 783.3 & 379.3 \\
\hline$n-\mathrm{C}_{5} \mathrm{H}_{12}$ (neopentane) & 799.0 & 378.2 \\
\hline $\mathrm{C}_{6} \mathrm{H}_{14}$ (hexane) & 861.5 & 364.4 \\
\hline$C_{7}+$ & 1005.0 & 276.2 \\
\hline
\end{tabular}

Table 3-A Study \#1 critical temperature and pressure correlation results for the $4 \mathrm{~nm}$ pore size.

\begin{tabular}{|c|c|c|}
\hline \multicolumn{3}{|c|}{$4 \mathrm{~nm}$ Pore Size Tc and Pc Correlation } \\
\hline Component & $T_{C},{ }^{o} R$ & $P_{c}, p s i a$ \\
\hline $\mathrm{CO}_{2}$ (Carbon Dioxide) & 536.8 & 1341.7 \\
\hline $\mathbf{N}_{2 \text { (Nitrogen Gas) }}$ & 223.2 & 589.0 \\
\hline $\mathrm{H}_{2} \mathrm{~S}$ (Hydrogen Sulfide) & 1209.6 & 19198.2 \\
\hline $\mathrm{CH}_{4}$ (Methane) & 338.1 & 755.5 \\
\hline $\mathrm{C}_{2} \mathrm{H}_{6}$ (Ethane) & 540.0 & 853.7 \\
\hline $\mathrm{C}_{3} \mathrm{H}_{8 \text { (propane) }}$ & 652.5 & 772.4 \\
\hline$i-\mathrm{C}_{4} \mathrm{H}_{10}$ (isobutane) & 719.1 & 683.7 \\
\hline$n-C_{4} H_{10}$ (butane) & 749.2 & 712.2 \\
\hline$i-\mathrm{C}_{5} \mathrm{H}_{12}$ (isopentane) & 810.3 & 649.8 \\
\hline$n-\mathrm{C}_{5} \mathrm{H}_{12}$ (neopentane) & 826.5 & 647.8 \\
\hline $\mathrm{C}_{6} \mathrm{H}_{14}$ (hexane) & 892.4 & 644.2 \\
\hline$c_{7}+$ & 863.7 & 519.6 \\
\hline
\end{tabular}


Table 4-A Study \#1 critical temperature and pressure correlation results for the $5 \mathrm{~nm}$ pore size.

\begin{tabular}{|c|c|c|}
\hline \multicolumn{3}{|c|}{$5 \mathrm{~nm}$ Pore Size Tc and Pc Correlation } \\
\hline Component & $T_{C},{ }^{o} R$ & $P_{c}, p s i a$ \\
\hline $\mathrm{CO}_{2}$ (Carbon Dioxide) & 540.0 & 1613.9 \\
\hline $\mathbf{N}_{2 \text { (Nitrogen Gas) }}$ & 224.4 & 701.1 \\
\hline $\mathrm{H}_{2} \mathrm{~S}$ (Hydrogen Sulfide) & 1209.6 & 19198.2 \\
\hline $\mathrm{CH}_{4}$ (Methane) & 339.6 & 895.4 \\
\hline $\mathrm{C}_{2} \mathrm{H}_{6}$ (Ethane) & 542.9 & 1016.7 \\
\hline $\mathrm{C}_{3} \mathrm{H}_{8 \text { (propane) }}$ & 656.5 & 922.8 \\
\hline$i-C_{4} H_{10}$ (isobutane) & 723.7 & 819.0 \\
\hline$n-C_{4} H_{10}$ (butane) & 754.1 & 853.1 \\
\hline$i-C_{5} H_{12}$ (isopentane) & 815.8 & 779.9 \\
\hline$n-\mathrm{C}_{5} \mathrm{H}_{12}$ (neopentane) & 832.2 & 777.6 \\
\hline $\mathrm{C}_{6} \mathrm{H}_{14}$ (hexane) & 898.7 & 774.6 \\
\hline$C_{7}+$ & 1051.7 & 627.1 \\
\hline
\end{tabular}

Table 5-A Study \#1 critical temperature and pressure results for the unconfined pore size.

\begin{tabular}{|c|c|c|}
\hline Component & TC, oR & PC, psia \\
\hline CO2 (Carbon Dioxide) & 547.7 & 1073.0 \\
\hline N2 (Nitrogen Gas) & 227.0 & 493.0 \\
\hline H2S(Hydrogen Sulfide) & 672.0 & 1306.0 \\
\hline CH4 (Methane) & 343.3 & 673.1 \\
\hline C2H6 (Ethane) & 549.8 & 708.3 \\
\hline C3H8 (propane) & 666.0 & 617.4 \\
\hline i-C4H10 (isobutane) & 734.7 & 529.1 \\
\hline n-C4H10 (butane) & 765.3 & 550.7 \\
\hline i-C5H12 (isopentane) & 829.8 & 483.0 \\
\hline n-C5H12 (neopentane) & 845.6 & 489.5 \\
\hline C6H14 (hexane) & 914.0 & 439.7 \\
\hline C7+ & 1070.3 & 369.6 \\
\hline
\end{tabular}


Table 6-A Study \#2 Critical Temperature and Pressure correlation results.

\begin{tabular}{|c|c|c|c|c|c|c||}
\hline & \multicolumn{2}{|c|}{$2 \mathrm{~nm}$} & \multicolumn{2}{c|}{$4 \mathrm{~nm}$} & \multicolumn{2}{c|}{$5 \mathrm{~nm}$} \\
\hline Component & $\begin{array}{c}\text { Critical } \\
\text { Temperature } \\
0^{\circ} \mathrm{R}\end{array}$ & $\begin{array}{c}\text { Critical } \\
\text { Pressure } \\
\text { psia }\end{array}$ & $\begin{array}{c}\text { Critical } \\
\text { Temperature } \\
{ }^{\circ} \mathrm{R}\end{array}$ & $\begin{array}{c}\text { Critical } \\
\text { Pressure } \\
\text { psia }\end{array}$ & $\begin{array}{c}\text { Critical } \\
\text { Temperature } \\
{ }^{\circ} \mathrm{R}\end{array}$ & $\begin{array}{c}\text { Critical } \\
\text { Pressure } \\
\text { psia }\end{array}$ \\
\hline $\boldsymbol{C O}_{\mathbf{2}}$ & 520.9 & 520.9 & 536.8 & 536.8 & 540.0 & 540.0 \\
\hline $\boldsymbol{N}_{\mathbf{2}}$ & 217.4 & 217.4 & 223.2 & 223.2 & 224.4 & 224.4 \\
\hline $\boldsymbol{H}_{\mathbf{2}} \boldsymbol{S}$ & 0.0 & 0.0 & 0.0 & 0.0 & 0.0 & 0.0 \\
\hline $\boldsymbol{C H}_{\mathbf{4}}$ & 330.7 & 330.7 & 338.1 & 338.1 & 339.6 & 339.6 \\
\hline $\boldsymbol{C}_{\mathbf{2}} \boldsymbol{H}_{\mathbf{6}}$ & 525.5 & 525.5 & 540.0 & 540.0 & 542.9 & 542.9 \\
\hline $\boldsymbol{C}_{\mathbf{3}} \boldsymbol{H}_{\mathbf{8}}$ & 633.2 & 633.2 & 652.5 & 652.5 & 656.5 & 656.5 \\
\hline $\boldsymbol{i}-\boldsymbol{C}_{\mathbf{4}} \boldsymbol{H}_{\mathbf{1 0}}$ & 696.3 & 696.3 & 719.1 & 719.1 & 723.7 & 723.7 \\
\hline $\boldsymbol{n}-\boldsymbol{C}_{\mathbf{4}} \boldsymbol{H}_{\mathbf{1 0}}$ & 725.5 & 725.5 & 749.2 & 749.2 & 754.1 & 754.1 \\
\hline $\boldsymbol{i}-\boldsymbol{C}_{\mathbf{5}} \boldsymbol{H}_{\mathbf{1 2}}$ & 783.3 & 783.3 & 810.3 & 810.3 & 815.8 & 815.8 \\
\hline $\boldsymbol{n}-\boldsymbol{C}_{\mathbf{5}} \boldsymbol{H}_{\mathbf{1 2}}$ & 799.0 & 799.0 & 826.5 & 826.5 & 832.2 & 832.2 \\
\hline $\boldsymbol{C}_{\boldsymbol{6}} \boldsymbol{H}_{\mathbf{1 4}}$ & 861.5 & 861.5 & 892.4 & 892.4 & 898.7 & 898.7 \\
\hline $\boldsymbol{C}_{\mathbf{7}}$ & 1003.5 & 1003.5 & 1043.1 & 1043.1 & 1051.2 & 1051.2 \\
\hline \hline
\end{tabular}

Table 7-A Pseudo critical temperature and pressure for the unconfined case in study \#1.

\begin{tabular}{|c|c|c|c|c|c|c|}
\hline Component & Mole Fraction & Corrected Mole Frac. & $T_{C},{ }^{0} R$ & $y \times T C$ & $P_{c}, p s i a$ & $y \times P C$ \\
\hline $\mathrm{CO}_{2}$ (Carbon Dioxide) & 0.00156 & 0.00156 & 547.7 & 0.8544 & 1073.0 & 1.67388 \\
\hline $\mathbf{N}_{\mathbf{2} \text { (Nitrogen Gas) }}$ & 0.00465 & 0.00465 & 227.0 & 1.0556 & 493.0 & 2.29245 \\
\hline $\mathrm{H}_{2} \mathrm{~S}$ (Hydrogen Sulfide) & 0.00000 & 0.00000 & 672.0 & 0.0000 & 1306.0 & 0 \\
\hline $\mathrm{CH}_{4}$ (Methane) & 0.77299 & 0.77299 & 343.3 & 265.3675 & 673.1 & 520.29957 \\
\hline $\mathrm{C}_{2} \mathrm{H}_{6}$ (Ethane) & 0.14775 & 0.14775 & 549.8 & 81.2330 & 708.3 & 104.65133 \\
\hline $\mathrm{C}_{3} \mathrm{H}_{8 \text { (propane) }}$ & 0.04885 & 0.04885 & 666.0 & 32.5341 & 617.4 & 30.15999 \\
\hline$i-\mathrm{C}_{4} \mathrm{H}_{10}$ (isobutane) & 0.00573 & 0.00573 & 734.7 & 4.2098 & 529.1 & 3.031743 \\
\hline$n-C_{4} H_{10}$ (butane) & 0.01156 & 0.01156 & 765.3 & 8.8469 & 550.7 & 6.366092 \\
\hline$i-\mathrm{C}_{5} \mathrm{H}_{12}$ (isopentane) & 0.00239 & 0.00239 & 829.8 & 1.9832 & 483.0 & 1.15437 \\
\hline$n-\mathrm{C}_{5} \mathrm{H}_{12}$ (neopentane) & 0.00230 & 0.00230 & 845.6 & 1.9449 & 489.5 & 1.12585 \\
\hline $\mathrm{C}_{6} \mathrm{H}_{14}$ (hexane) & 0.00129 & 0.00129 & 914.0 & 1.1791 & 439.7 & 0.567213 \\
\hline \multirow[t]{2}{*}{$c_{7}+$} & 0.00093 & 0.00093 & 1070.3 & 0.9954 & 369.6 & 0.3437168 \\
\hline & 1.00000 & 1.00000 & & 400.20 & & 671.67 \\
\hline
\end{tabular}


Table 8-A Pseudo critical temperature and pressure for the $2 \mathrm{~nm}$ pore size case in study \#1.

\begin{tabular}{|c|c|c|c|c|c|c|}
\hline Component & Mole Fraction & Corrected Mole Frac. & $T_{C}{ }^{0} R$ & $y \times T C$ & $P_{C}, p s i a$ & $y \times P C$ \\
\hline $\mathrm{CO}_{2}$ (Carbon Dioxide) & 0.00156 & 0.00156 & 985.9 & 1.5379 & 854.5 & 1.3330142 \\
\hline$N_{2 \text { (Nitrogen Gas) }}$ & 0.00465 & 0.00465 & 217.4 & 1.0107 & 405.6 & 1.8862699 \\
\hline $\mathrm{H}_{2} \mathrm{~S}_{\text {(Hydrogen Sulfide) }}$ & 0.00000 & 0.00000 & 1209.6 & 0.0000 & 1306.0 & 0 \\
\hline $\mathrm{CH}_{4}$ (Methane) & 0.77299 & 0.77299 & 330.7 & 255.5927 & 572.1 & 442.20716 \\
\hline $\mathrm{C}_{2} \mathrm{H}_{6}$ (Ethane) & 0.14775 & 0.14775 & 525.5 & 77.6429 & 580.8 & 85.808847 \\
\hline $\mathrm{C}_{3} \mathrm{H}_{8 \text { (propane) }}$ & 0.04885 & 0.04885 & 696.3 & 34.0132 & 491.7 & 24.021671 \\
\hline$i-\mathrm{C}_{4} \mathrm{H}_{10}$ (iso-butane) & 0.00573 & 0.00573 & 725.5 & 4.1568 & 432.0 & 2.4754034 \\
\hline $\mathrm{n}-\mathrm{C}_{4} \mathrm{H}_{10}$ (butane) & 0.01156 & 0.01156 & 696.3 & 8.0490 & 414.7 & 4.7942473 \\
\hline$i-\mathrm{C}_{5} \mathrm{H}_{12}$ (isopentane) & 0.00239 & 0.00239 & 783.3 & 1.8722 & 379.3 & 0.9065568 \\
\hline$n-\mathrm{C}_{5} \mathrm{H}_{12}$ (neopentane) & 0.00230 & 0.00230 & 799.0 & 1.8377 & 378.2 & 0.8698065 \\
\hline $\mathrm{C}_{6} \mathrm{H}_{14}$ (hexane) & 0.00129 & 0.00129 & 861.5 & 1.1114 & 364.4 & 0.4701212 \\
\hline $\mathrm{C}_{7}+$ & 0.00093 & 0.00093 & 1005.0 & 0.9346 & 276.2 & 0.2568603 \\
\hline & 1.00000 & 1.00000 & & 387.76 & & 565.03 \\
\hline
\end{tabular}

Table 9-A Pseudo critical temperature and pressure for the $4 \mathrm{~nm}$ pore size case in study \#1.

\begin{tabular}{|c|c|c|c|c|c|c|}
\hline Component & Mole Fraction & Corrected Mole Frac. & $T_{C},{ }^{0} R$ & $y \times T C$ & $P_{c}, p s i a$ & $y \times P C$ \\
\hline $\mathrm{CO}_{2}$ (Carbon Dioxide) & 0.00156 & 0.00156 & 536.8 & 0.8374 & 1341.7 & 2.0930268 \\
\hline$N_{2 \text { (Nitrogen Gas) }}$ & 0.00465 & 0.00465 & 223.2 & 1.0379 & 589.0 & 2.73903 \\
\hline $\mathrm{H}_{2} \mathrm{~S}$ (Hydrogen Sulfide) & 0.00000 & 0.00000 & 1209.6 & 0.0000 & 19198.2 & 0 \\
\hline $\mathrm{CH}_{4}$ (Methane) & 0.77299 & 0.77299 & 338.1 & 261.3456 & 755.5 & 583.96761 \\
\hline $\mathrm{C}_{2} \mathrm{H}_{6}$ (Ethane) & 0.14775 & 0.14775 & 540.0 & 79.7792 & 853.7 & 126.12864 \\
\hline $\mathrm{C}_{3} \mathrm{H}_{8 \text { (propane) }}$ & 0.04885 & 0.04885 & 652.5 & 31.8756 & 772.4 & 37.730176 \\
\hline $\mathrm{i}-\mathrm{C}_{4} \mathrm{H}_{10}$ (isobutane) & 0.00573 & 0.00573 & 719.1 & 4.1203 & 683.7 & 3.917818 \\
\hline$n-\mathrm{C}_{4} \mathrm{H}_{10}$ (butane) & 0.01156 & 0.01156 & 749.2 & 8.6607 & 712.2 & 8.233343 \\
\hline$i-\mathrm{C}_{5} \mathrm{H}_{12}$ (isopentane) & 0.00239 & 0.00239 & 810.3 & 1.9366 & 649.8 & 1.5529829 \\
\hline$n-\mathrm{C}_{5} \mathrm{H}_{12}$ (neopentane) & 0.00230 & 0.00230 & 826.5 & 1.9009 & 647.8 & 1.490028 \\
\hline $\mathrm{C}_{6} \mathrm{H}_{14}$ (hexane) & 0.00129 & 0.00129 & 892.4 & 1.1512 & 644.2 & 0.8310453 \\
\hline \multirow[t]{2}{*}{$C_{7}+$} & 0.00093 & 0.00093 & 863.7 & 0.8032 & 519.6 & 0.4832333 \\
\hline & 1.00000 & 1.00000 & & 393.45 & & 769.17 \\
\hline
\end{tabular}


Table 10-A Pseudo critical temperature and pressure for the $5 \mathrm{~nm}$ pore size case in study \#1.

\begin{tabular}{|c|c|c|c|c|c|c|}
\hline Component & Mole Fraction & Corrected Mole Frac. & $T_{C},{ }^{0} R$ & $y \times T C$ & $P_{c}, p s i a$ & $y \times P C$ \\
\hline $\mathrm{CO}_{2}$ (Carbon Dioxide) & 0.00156 & 0.00156 & 540.0 & 0.8424 & 1613.9 & 2.5176864 \\
\hline $\mathbf{N}_{\mathbf{2} \text { (Nitrogen Gas) }}$ & 0.00465 & 0.00465 & 224.4 & 1.0435 & 701.1 & 3.2601692 \\
\hline $\mathrm{H}_{2} \mathrm{~S}$ (Hydrogen Sulfide) & 0.00000 & 0.00000 & 1209.6 & 0.0000 & 19198.2 & 0 \\
\hline $\mathrm{CH}_{4}$ (Methane) & 0.77299 & 0.77299 & 339.6 & 262.5111 & 895.4 & 692.17133 \\
\hline $\mathrm{C}_{2} \mathrm{H}_{6}$ (Ethane) & 0.14775 & 0.14775 & 542.9 & 80.2145 & 1016.7 & 150.2117 \\
\hline $\mathrm{C}_{3} \mathrm{H}_{8 \text { (propane) }}$ & 0.04885 & 0.04885 & 656.5 & 32.0688 & 922.8 & 45.079448 \\
\hline$i-\mathrm{C}_{4} \mathrm{H}_{10}$ (isobutane) & 0.00573 & 0.00573 & 723.7 & 4.1470 & 819.0 & 4.6926699 \\
\hline$n-C_{4} H_{10}$ (butane) & 0.01156 & 0.01156 & 754.1 & 8.7170 & 853.1 & 9.8617045 \\
\hline$i-\mathrm{C}_{5} \mathrm{H}_{12}$ (isopentane) & 0.00239 & 0.00239 & 815.8 & 1.9499 & 779.9 & 1.8639813 \\
\hline$n-\mathrm{C}_{5} \mathrm{H}_{12}$ (neopentane) & 0.00230 & 0.00230 & 832.2 & 1.9139 & 777.6 & 1.7884188 \\
\hline $\mathrm{C}_{6} \mathrm{H}_{14}$ (hexane) & 0.00129 & 0.00129 & 898.7 & 1.1594 & 774.6 & 0.9992268 \\
\hline \multirow[t]{2}{*}{$c_{7}+$} & 0.00093 & 0.00093 & 1051.7 & 0.9780 & 627.1 & 0.5831619 \\
\hline & 1.00000 & 1.00000 & & 395.55 & & 913.03 \\
\hline
\end{tabular}




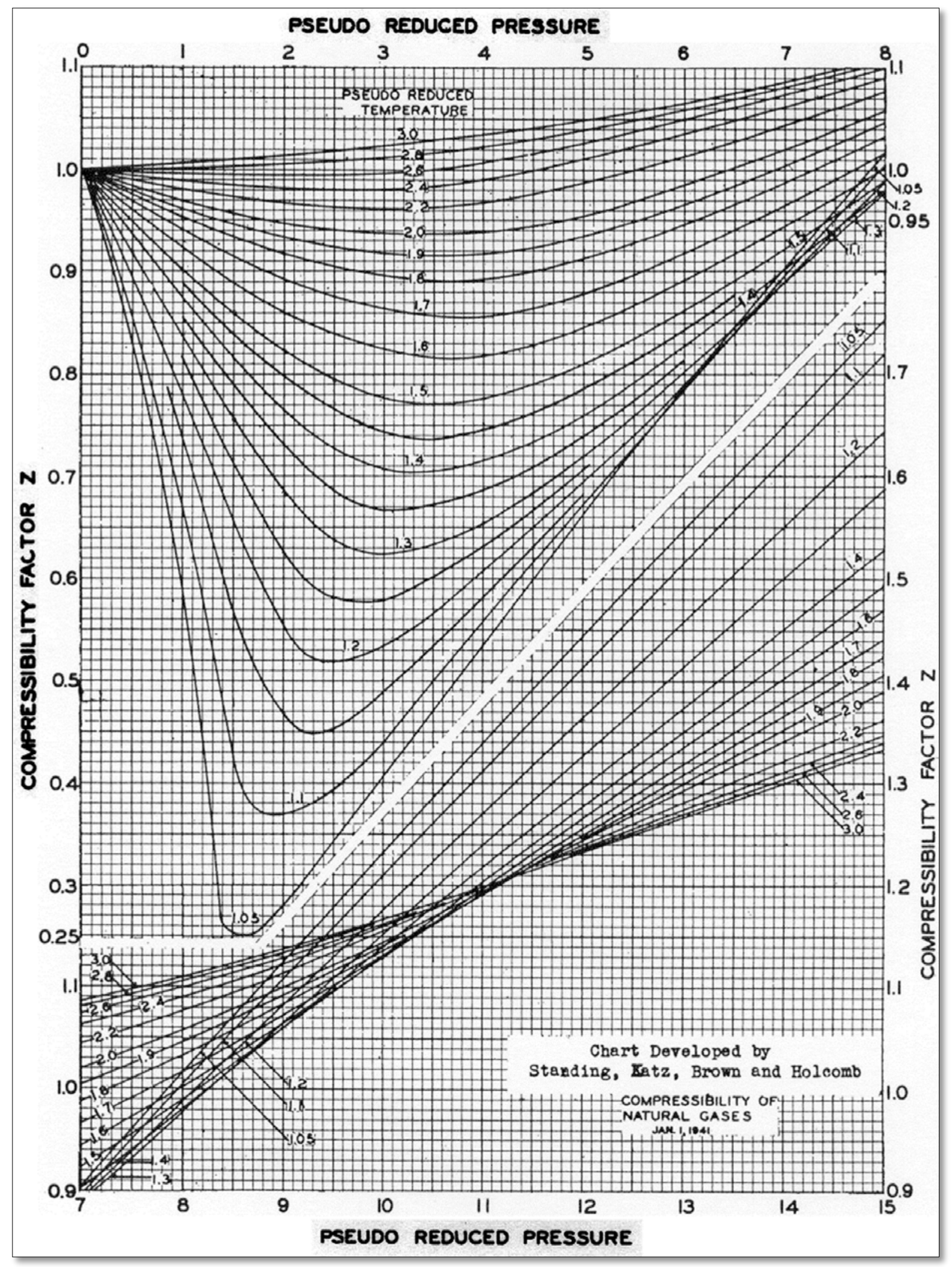

Figure 1-Z-Factor or compressibility chart. 